\title{
The money-age distribution:
}

\section{Empirical facts and limited monetary models*}

\author{
Burkhard Heer ${ }^{a, b}$, Alfred Maussner ${ }^{c}$ and Paul D. McNelis ${ }^{d}$
}

${ }^{a}$ Free University of Bolzano-Bozen, School of Economics and Management, Via Sernesi 1, 39100 Bolzano, Italy, Burkhard.Heer@unibz.it

${ }^{b}$ CESifo, Munich, Germany

${ }^{c}$ University of Augsburg, Department of Economics, Universitätsstrasse 16, 86159 Augsburg, Germany, alfred.maussner@wiwi.uni-augsburg.de

${ }^{d}$ Fordham University, Graduate School of Business Administration, 113 W. 60th St., New York, NY 10023-7484, mcnelis@fordham.edu

Preliminary version: January 18, 2007

JEL classification: E41, E31, D30

Key Words: Money-Age Distribution, Money Demand, OLG Model

\begin{abstract}
:
The money-age distribution is hump-shaped for the US post-war economy. There is no clear cut relation between the variation of money holdings within generations and age. Furthermore, money is found to be only weakly correlated with both income and wealth. We analyze three motives for money demand in an overlapping generations model in order to explain these observations: 1) money in the utility, 2) an economy with costly credit service, and 3) limited participation. All three models are consistent with the hump-shaped relation between average money holdings and age, yet they predict a much closer association between money holdings, income, wealth, and age than we find in the data. Only the limited-participation model partly replicates the low bivariate correlation between money and income as well as between money and interest bearing assets. None of the three models satisfactorily explains these stylized facts.
\end{abstract}

* Preliminary versions of this paper have been presented at the CESifo area conference on Money, Macro and International Finance in Munich, the CEF conference in Cyprus, the Annual Meeting of the German Economic Association in Bayreuth, and at seminars at the Catholic University of Leuven, and the universities of Bilbao and Hamburg. We would like to thank Kenneth Judd and Kenneth Kletzer for helpful comments. All remaining errors are ours. Burkhard Heer kindly acknowledges support from the German Science Foundation (Deutsche Forschungsgemeinschaft DFG) during his stays at Georgetown University, University of Pennsylvania, and Stanford University. 


\section{Introduction}

The dynamic general equilibrium (DGE) literature has discussed the distribution of income and wealth, but has ignored the distribution of money. Díaz-Giménez, Quadrini and RíosRull (1997) document the facts on the U.S. Distribution of earnings, income, and wealth. Earnings and income are much less concentrated than and are only weakly correlated with wealth. Huggett (1996) shows that these facts can be replicated in a satisfactory manner in an OLG model where agents are characterized by heterogeneous productivity and receive social security. Huggett and Ventura (2000) also explain the consumption behavior over the life-cycle and explain why low-income households do not save.

To the best of our knowledge there is no comparable study on the money distribution over the life cycle. We use empirical evidence from the US to document the following stylized facts:

1. money holdings are hump-shaped over the life-cycle,

2. that there is no clear-cut relation between the variation of money holdings and age, and

3. that income, wealth, and age explain only a small fraction of the variation of money holdings.

This empirical evidence is found to be stable over time.

We develop three alternative monetary general equilibrium models in order to explain the heterogeneity of money holdings across individuals. They differ in the way money is introduced. We compare the following approaches:

1. Money in the utility function, in which households save in the form of money or capital.

2. Costly credit. Households can consume a continuum of commodities that can be purchased with either money or credit. Credit, however, is costly, as in Dotsey and Ireland (1996). Again, money is a poor store of value since it is dominated in return by capital. 
3. Limited participation. Firms need to finance wage expenditures with a loan, while households deposit part of their money at a bank. The central bank injects the money into the banking sector after the households have made the deposits, but before the firms ask for a loan.

We find that all three models explain the hump-shaped pattern between average money holdings and age but fail to produce the low predictive power of income, wealth, and age for the distribution of money holdings. The limited-participation model, however, can account for the low bivariate correlation between income and money and between money and household's holdings of interest-bearing assets. Therefore, our results suggest that a cash-in-advance constraint should be specified so that the households can use wage income in order to finance consumption.

The remainder of the paper is structured as follows. Section 2 documents the empirical facts of the money-age distribution for the US economy. Section 3 introduces the overlappinggenerations model with two assets, money and capital. The model is calibrated with regard to the characteristics of the US economy in Section 4. Our numerical results are presented in Section 5. Section 6 concludes. ${ }^{1}$

\section{Empirical observations}

We use data from the 1994, 1999, and 2001 University of Michigan Personal Survey of Income Dynamics (PSID) family, income, and wealth files. These are the only three data sets for which we are able to match data on income, age, money and capital. ${ }^{2}$ Our data set includes families with strictly positive money holdings where the head of household is of age between 20 and 80 . This gives us 15,875 observations.

To analyze the money holding behavior depending on age in Figure 2, we group the households in the following age categories: 20-24, 25-29, 30-34, 35-39, 40-44, 45-49, 50-54, 55-59, 60-64, 65-69, 70-74, 75-80. Money, $M$, is defined as money in checking or savings accounts,

\footnotetext{
${ }^{1}$ An Appendix covers additional empirical evidence and explains the computational solution of our models.

${ }^{2}$ For this reason it makes no sense to control for cohort effects in the computation of the inequality of money holdings as is done by Storesletten, Telmer, and Yaron (2004).
} 
Figure 1: Distribution of income, earnings, money, and wealth

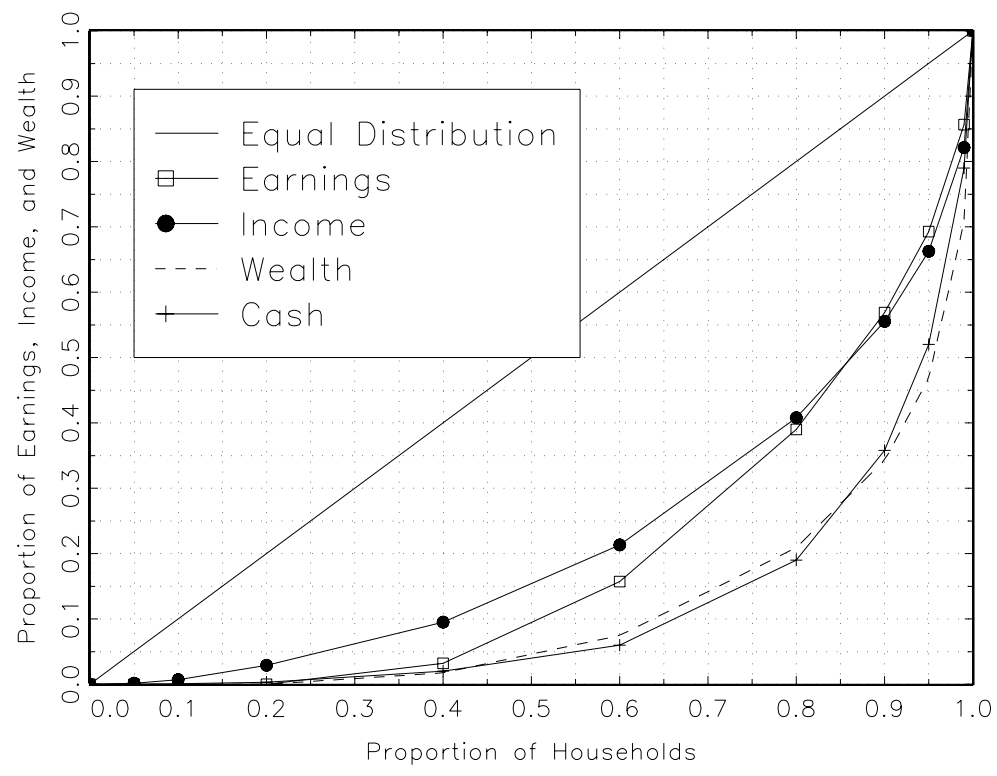

money market funds, certificates of deposit, government savings bonds, and treasury bills. ${ }^{3}$ Capital, $k$, consists of shares of stock in publicly held corporations, mutual funds, and investment funds and other savings or assets, such as bond funds and life insurance policies. Total family income is made of taxable and transfer income of head, wife, and other family unit members and Social Security Income. In addition to the PSID data we use data for income, earnings, and wealth from the Survey of Consumer Finances 1992.

We observe the following regularities: ${ }^{4}$

1. Money is much more concentrated than income or wealth and almost as unequally distributed as wealth. See Figure 1, which displays data from the Survey of Consumer Finances 1992.

2. Money $M$ is only weakly correlated with income and capital (see Table 1 ).

\footnotetext{
${ }^{3}$ We are aware that this definition of money in the PSID data does not match the definition of money as a purely non-interest bearing asset as it appears in our model. Yet, the PSID wealth files do not make this distinction.

${ }^{4}$ The Appendix demonstrates that most of the findings reported below are not a feature of pooling but also emerge in the individual data sets.
} 
Figure 2: Cash holdings over the life-cycle
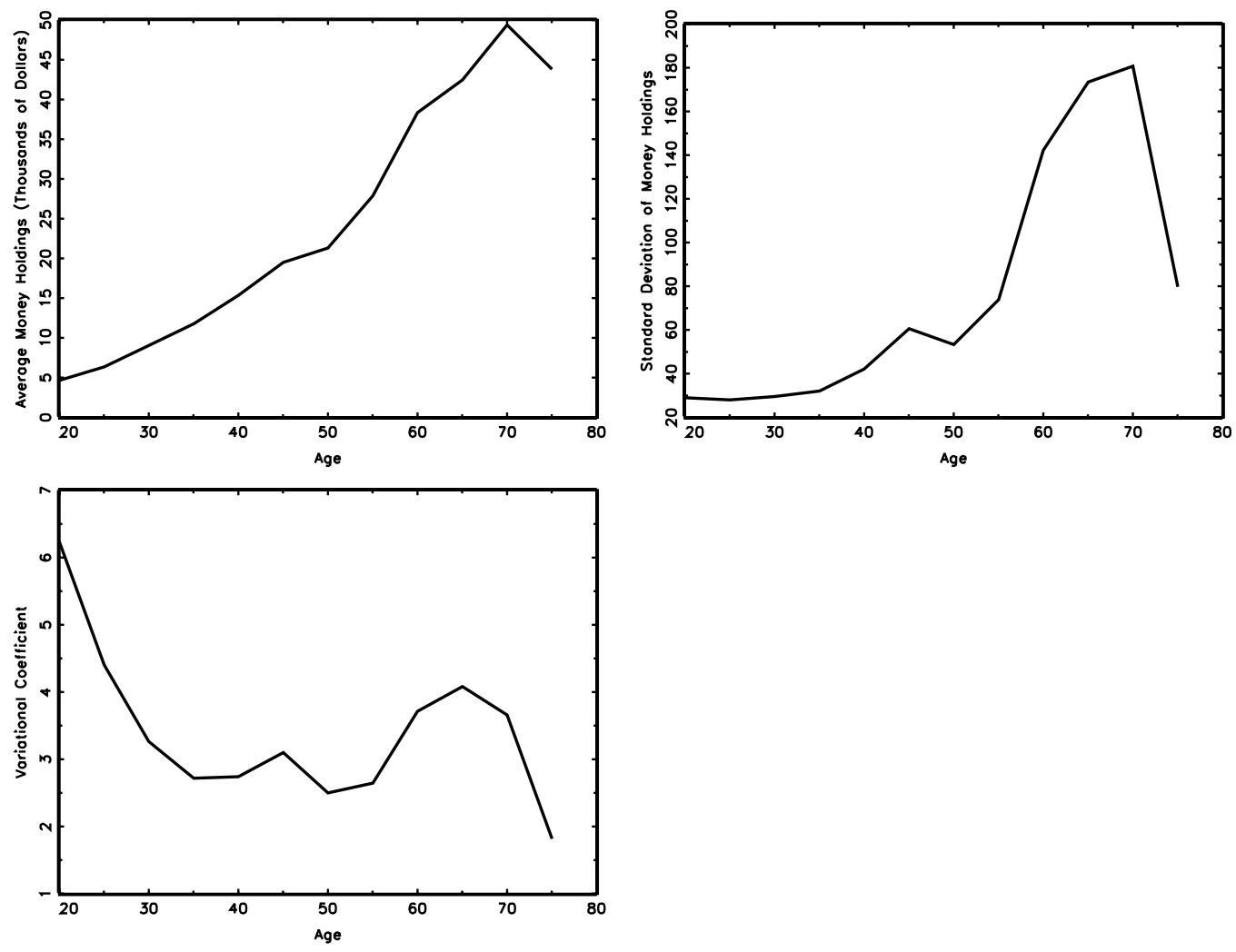

Table 1: Empircal correlations

\begin{tabular}{cccc}
\hline \hline Year & money/income & money/capital & capital/income \\
\hline 1994 & 0.21 & 0.18 & 0.21 \\
1999 & 0.20 & 0.28 & 0.12 \\
2001 & 0.26 & 0.29 & 0.11 \\
\hline
\end{tabular}


Table 2: Regressions of money holdings on income, wealth, and age

\begin{tabular}{ccccccc}
\hline \hline income & income $^{2}$ & wealth & wealth $^{2}$ & age & age $^{2}$ & $R^{2}$ \\
\hline 0.33 & -0.00 & 0.01 & 0.00 & -1.74 & 0.03 & 0.14 \\
$(5.84)$ & $(-3.96)$ & $(1.27)$ & $(2.52)$ & $(-4.20)$ & $(5.50)$ & \\
0.33 & -0.00 & 0.01 & 0.00 & -1.79 & 0.03 & 0.12 \\
$(5.46)$ & $(-4.36)$ & $(1.01)$ & $(0.94)$ & $(-4.40)$ & $(5.61)$ & \\
\hline
\end{tabular}

Notes: Fixed effects estimation. Estimates of the constant terms are not displayed. The estimates reported in the first row use capital as an indicator of wealth. Those reported in the second row use total wealth minus money holdings as indicator of family wealth. Robust $t$-ratios in parenthesis

3. Cash holdings increase steadily over most of the life-cycle and decrease at ages 75-80 so that a hump-shaped pattern emerges. See the upper left panel in Figure 2.

4. The standard deviation of money is hump-shaped as well. See the upper right panel in Figure 2.

5. The dispersion as measured by the coefficient of variation of money holdings has no obvious relation to age. See the lower left panel in Figure 2.

6. When we regress money on income, income squared, capital, capital squared, age, and age squared, we find that money holdings increase with income (this relation is significantly hump-shaped) and decrease with age (this relation is u-shaped). This also holds, when we use total family wealth less money holdings as our definition of wealth. Yet, Table 2 also shows that these variables explain only a small share of the variation of money holdings over income and age groups.

\section{The model}

As mentioned above, we use a general equilibrium overlapping generations model with three different frameworks for money demand: the use of money as an argument in the household utility function, the device of differentiating cash and credit goods, and limited 
participation by households in the financial system (restricting their savings to deposits in the banking system).

Four sectors appear in the model: households, production, banking, and the government. Households maximize discounted life-time utility. Agents can save either with money or with capital. Individuals are heterogeneous with regard to their productivity and cannot insure against idiosyncratic income risk. Firms maximize profits. Output is produced with the help of labor and capital. The government collects taxes from labor and interest income in order to finance its expenditures on government consumption. The government also provides social security and controls the money supply. In the limited-participation model, banks receive deposits from households and lend them to firms. We restrict our analysis to steady-state behavior. For simplicity of notation we drop the time indices of our variables whenever appropriate.

\subsection{Households}

Every year a generation of equal measure is born. The total measure of all generations is normalized to one. As we only study steady-state behavior, we concentrate on the behavior of an individual $h$ born in period 0 . His first period of life is period $s=1$. We use $s$ to refer the age of agent $h$. The total measure of all households is normalized to one.

Households live a maximum of $T$ years. Lifetime is stochastic and agents face a probability $\phi_{s}$ of surviving up to age $s$ conditional on surviving up to age $s-1$. During their first $R-1$ years, agents supply one unit of labor inelastically. After $R$ years, retirement is mandatory. Workers are heterogeneous with regard to their labor earnings. Labor earnings $e\left(s, z_{h}\right) w$ are stochastic and depend on individual age $s$, an idiosyncratic labor productivity shock $z_{h}$, and the wage rate $w$. Furthermore, agents hold two kinds of assets, real money $m=M / P$ and capital $k$, where $M$ and $P$ denote nominal money and the price level, respectively. The household $h$ is born without any capital:, $k_{h 1} \equiv 0$. In the money-in the utility function model, the first generation is endowed with a strictly positive amount of nominal money, $M_{h 1}=\bar{M}_{h 0} \cdot{ }^{5}$ Capital or, equally, equity $k$ earns a real interest rate $r$. Parents do not leave altruistic bequests to their children. All accidental bequests are confiscated by the state.

\footnotetext{
${ }^{5}$ Otherwise, the level of utility at age 1 is not well-defined. The calibration of $\bar{M}_{h 0}$ is discussed in section 4 .
} 
The household $h$ maximizes life-time utility:

$$
\left[\sum_{s=1}^{T} \beta^{s-1}\left(\Pi_{j=1}^{s} \phi_{s}\right) u(\cdot),\right]
$$

where $\beta$ denotes the discount factor.

In our first case, we simply consider money in the utility:

$$
\text { case 1: } \quad u(c, m)=\frac{\left(c^{\gamma} m^{1-\gamma}\right)^{1-\sigma}}{1-\sigma}
$$

where $c, m$, and $\sigma>0$ denote consumption, real-money balances, and the coefficient of relative risk aversion, respectively. ${ }^{6}$

In our second specification, consumers can purchase consumption with cash or credit as in Schreft (1992), Gillman (1993), or Dotsey and Ireland (1996). The consumption goods are indexed by $i \in[0,1]$, and the consumption aggregator is given by $c=\inf _{i}\{c(i)\}$. Therefore, the individuals will consume the same amount of all goods as in Schreft (1992). Utility $u(\cdot)$ is of the form

$$
\text { cases } 2 \text { and } 3: \quad u(c)=\frac{c^{1-\sigma}}{1-\sigma} .
$$

In order to buy an amount $c$ of good $i$ with credit, the household must purchase $\kappa(c, i)$ units of financial services. The function $\kappa(.,$.$) is weakly increasing in c$, strictly increasing in $i$, and satisfies $\lim _{i \rightarrow 1} \kappa(c, i)=\infty$ for all $c \geq 0$. According to the latter assumption, some goods will be purchased with cash, and the demand for money is well defined. In particular, the transaction technology is given by the sum of a variable and a fixed costs term:

$$
\kappa(c, i)=\kappa_{0}\left(\frac{i}{1-i}\right)^{\chi}+\frac{\kappa_{1}}{c(i)} .
$$

For $\kappa_{1}=0$, fixed costs are zero, and the technology displays constant returns to scale. ${ }^{7}$

\footnotetext{
${ }^{6}$ We also considered a CES-index in consumption and real money balances, but found the results not superior to those implied by the Cobb-Douglas case considered in equation (2).

${ }^{7}$ Erosa and Ventura (2002) have shown that inflation does not affect (increases) wealth inequality in the case of constant (decreasing) returns to scale.
} 
Intermediation of credit services is subject to perfect competition, and in order to produce one unit of service one efficiency unit of labor is used. In equilibrium, the financial service companies make zero profit, and the fees $q$ per unit of financial service sold is equal to the wage rate $w$.

The household will purchase a fraction $\zeta \in[0,1)$ of consumption goods with credit. The household faces the following cash-in-advance constraint on the remaining purchases:

case 2: $\quad c_{h s}\left(1-\zeta_{h s}\right) \leq m_{h s}$.

In the third specification, households deposit part of the financial wealth at banks at the gross nominal interest $Q$. The firms pay wages to the households before they sell their output. To finance the wage bill, firms borrow money from the banking sector. The government injects the money into the banking sector. Crucially, banks receive the monetary transfer after households have made their deposits in the banking system.

Households hold financial wealth $M_{h s}=D_{h s}+X_{h s}$ where $D_{h s}$ is the amount deposited at banks and $X_{h s}$ are money balances kept for the purchase of consumption goods. Since households receive wages before they go shopping, their cash-in-advance constraint is

$$
c_{h s} \leq \begin{cases}x_{h s}+\left(1-\tau_{w}-\theta\right) w_{t} e\left(s, z_{h}\right) & s<R, \\ x_{h s}+b\left(\bar{e}_{h s}\right), & s \geq R .\end{cases}
$$

where $x, \tau_{w}$, and $\theta$ denote real money balances, labor income taxes, and social security contributions, respectively. Furthermore, cash holdings cannot be negative, $x \geq 0$.

The $s$-year old agent $h$ receives income from capital $k_{h s}$ and labor $e\left(s, z_{h}\right) w$ in each period $s$ of his life. After retirement agents do not work, $e\left(s, z_{h}\right)=0$ for $s \geq R$. The budget constraint of the $s$-year old household $h$ is given by: ${ }^{8}$

$$
\begin{aligned}
\left(1-\tau_{r}\right) r k_{h s} & +\left(1-\tau_{w}-\theta\right) w e\left(s, z_{h}\right)+b\left(\bar{e}_{h s}\right)+t r+k_{h s}+m_{h s} \\
& = \begin{cases}c_{h s}+k_{h s+1}+m_{h s+1}(1+\pi)-\text { Seign } & \text { case } 1 \\
c_{h s}+w \int_{0}^{\zeta} \kappa(c, i) d i+k_{h s+1}+\pi m_{h s+1}-\text { Seign } & \text { case 2 } \\
c_{h s}-\left(1-\tau_{r}\right)(Q-1) d_{h s}+\Omega^{B}+k_{h s+1}+\pi m_{h s+1} & \text { case 3 }\end{cases}
\end{aligned}
$$

\footnotetext{
${ }^{8}$ At the end of the final period, $k_{h T+1}=M_{h T+1}^{h} \equiv 0$.
} 
where Seign and $\pi=P_{t} / P_{t-1}$ denote seignorage and the inflation factor between two successive periods $t-1$ and $t$, respectively.

Note that in the stationary equilibrium $\pi$ is a constant and equals the money growth factor. In cases 1 and 2, households receive the seignorage. In the limited participation model, the central bank injects the increase in the money supply into the banking sector, while households receive lump-sum profits from banks, $\Omega^{B}$, and earn interest $Q-1$ on their real deposits $d_{h s}$. Real interest income is taxed at the rate $\tau_{r}$.

In addition, the households receive transfers $t r$ from the government. Social security benefits $b\left(s, \bar{e}_{h}\right)$ depend on the agent's age $s$ as well as on an average of past earnings $\bar{e}_{h}$ of the household $h$. Following Huggett and Ventura (2000), social security benefits are composed of a lump-sum component and an earnings-related benefit:

$$
b\left(s, \bar{e}_{h}\right)= \begin{cases}0 & \text { for } s<R \\ b_{0}+b_{1}\left(\bar{e}_{h s}\right) & \text { for } s \geq R\end{cases}
$$

The function $b_{1}\left(\bar{e}_{h s}\right)$ is described in more detail in Section 4.

\subsection{Production}

Firms are of measure one and produce output with effective labor $N$ and capital $K$. Effective labor $N$ is paid the wage $w$. In the case of the limited participation model, firms have to pay workers in advance and have to borrow $w N$ at the nominal interest rate $Q-1$ in advance. Capital $K$ is hired at rate $r$ and depreciates at rate $\delta$. Production $Y$ is characterized by constant returns to scale and assumed to be Cobb-Douglas:

$$
Y=F(K, N)=K^{\alpha} N^{1-\alpha}
$$

In a factor market equilibrium, factors are rewarded with their marginal product:

$$
\begin{aligned}
(1-\alpha) K^{\alpha} N^{-\alpha} & = \begin{cases}w & \text { case } 1 \text { and } 2 \\
Q w & \text { case } 3\end{cases} \\
\alpha K^{\alpha-1} N^{1-\alpha}-\delta & =r .
\end{aligned}
$$

Consequently, profits are zero. 


\subsection{Banking sector}

In the limited participation model we also model a banking sector. At the beginning of period $t$ banks receive deposits of size $D_{t}$ from households. Government transfers the amount $M_{t+1}-M_{t}$ to the banks that are able to lend $D_{t}+M_{t+1}-M_{t}$ to firms. At the end of the period $t$ they pay interest and principal $Q D_{t}$ to their creditors and distribute the remaining real profits $\Omega^{B}$ to the households:

$$
\Omega_{t}^{B}=\frac{Q\left(D_{t}+M_{t+1}-M_{t}\right)}{P_{t}}-\frac{Q D_{t}}{P_{t}}=Q \frac{M_{t+1}-M_{t}}{P_{t}} .
$$

In a credit market equilibrium the supply of credit is equal to its demand:

$$
w_{t} N_{t}=\frac{D_{t}+M_{t+1}-M_{t}}{P_{t}}
$$

\subsection{Government}

The government consists of the fiscal and monetary authority. Nominal money grows at the exogenous rate $\mu$ :

$$
\frac{M_{t+1}-M_{t}}{M_{t}}=\mu \text {. }
$$

In cases 1 and 2, seignorage Seign $=M_{t+1}-M_{t}$ is transferred lump-sum. In case 3, money is injected into the banking sector.

The government uses the revenues from taxing income and aggregate accidental bequests $B e q$ in order to finance its expenditures on government consumption $G$, government transfers $t r$, and transfers to the one-year old households $\tilde{m}:^{9}$

$$
G+t r+\tilde{m}=\tau_{r} r k+\tau_{w} N+B e q .
$$

We assume that transfers $t r$ are distributed lump-sum to all households. Furthermore, the government provides social security benefits Pens that are financed by taxes on labor income:

$$
\text { Pens }=\theta w N .
$$

\footnotetext{
${ }^{9}$ Following Heer and Süssmuth (2007), we assume that in case 1 the first-period money balances are financed by the government.
} 


\subsection{Stationary equilibrium}

The concept of equilibrium applied in this paper uses a recursive representation of the consumer's problem following Stokey, Lucas, and Prescott (1989). Let $\varphi_{s}(k, m, d, \bar{e}, z)$ and $V_{s}(k, m, d, \bar{e}, z)$ denote the measure and the value of the objective function of the $s$-year old agent with equity $k$, real money $m$, deposits $d$, average earnings $\bar{e}$, and idiosyncratic productivity level $z$, respectively. $V_{s}(k, m, d, \bar{e}, z)$ is defined as the solution to the dynamic program:

$$
V_{s}(k, m, d, \bar{e}, z)=\max _{k^{\prime}, m^{\prime}, d^{\prime}, c}\left\{u+\beta \phi_{s+1} E\left[V_{s+1}\left(k^{\prime}, m^{\prime}, d^{\prime}, \bar{e}^{\prime}, z^{\prime}\right)\right]\right\}
$$

subject to (7), (5) and (7), (6) and (7) in cases 1, 2, and 3, respectively. $k^{\prime}, m^{\prime}, d^{\prime}, \bar{e}^{\prime}$, and $z^{\prime}$ denote the next-period value of $k, m, d, \bar{e}$, and $z$, respectively. Optimal decision rules at age $s$ are functions of $k, m, d, \bar{e}$, and $z$, i.e. consumption $c_{s}(k, m, d, \bar{e}, z)$, next period deposits $d_{s+1}(k, m, d, \bar{e}, z)$, next-period capital stock $k_{s+1}(k, m, d, \bar{e}, z)$, and nextperiod real money balances $m_{s+1}(k, m, d, \bar{e}, z)$. In cases 1 and 2 , deposits are zero, $d \equiv 0$. In case 2 , the optimal share of cash goods also depends on the individual state variables, $\zeta_{s}=\zeta_{s}(k, m, \bar{e}, z)$.

We will consider a stationary equilibrium where factor prices, aggregate capital, and labor are constant and the distribution of wealth is stationary.

\section{Definition}

A stationary equilibrium for a given government policy $\left\{\tau_{r}, \tau_{w}, \theta, G, \operatorname{tr}, b(\cdot), \mu\right\}$ is a collection of value functions $V_{s}(k, m, d, \bar{e}, z)$, individual policy rules $c_{s}(k, m, d, \bar{e}, z), k^{\prime}=$ $k_{s+1}(k, m, d, \bar{e}, z), m^{\prime}=m_{s+1}(k, m, d, \bar{e}, z), d^{\prime}=d_{s+1}(k, m, d, \bar{e}, z)$, and $\zeta(k, m, \bar{e}, z)$, relative prices of labor and capital $\{w, r\}$, and distributions $\left(\varphi_{1}(),. \ldots, \varphi_{T}().\right)$, such that: 
1. Individual and aggregate behavior are consistent:

$$
\begin{aligned}
N & =\sum_{s=1}^{T} \int_{k} \int_{m} \int_{d} \int_{\bar{e}} \int_{z} e(z, j) \varphi_{s}(k, m, d, \bar{e}, z) d z d \bar{e} d d d m d k \\
K & =\sum_{s=1}^{T} \int_{k} \int_{m} \int_{d} \int_{\bar{e}} \int_{z} k \varphi_{s}(k, m, d, \bar{e}, z) d z d \bar{e} d d d m d k \\
C & =\sum_{s=1}^{T} \int_{k} \int_{m} \int_{d} \int_{\bar{e}} \int_{z} c_{s}(k, m, d, \bar{e}, z) \varphi_{s}(k, m, d, \bar{e}, z) d z d \bar{e} d d d m d k \\
B e q & =\sum_{s=1}^{T} \int_{k} \int_{m} \int_{d} \int_{\bar{e}} \int_{z}\left(1-\phi_{s+1}\right) a_{s+1}(k, m, d, \bar{e}, z) \varphi_{s}(k, m, d, \bar{e}, z) d z d \bar{e} d d d m d k \\
\frac{M}{P} & =\sum_{s=1}^{T} \int_{k} \int_{m} \int_{d} \int_{\bar{e}} \int_{z} m \varphi_{s}(k, m, d, \bar{e}, z) d z d \bar{e} d d d m d k \\
\tilde{m} & =\int_{m} \int_{\bar{e}} \int_{z} m \varphi_{1}(0, m, 0, \bar{e}, z) d z d \bar{e} d m,
\end{aligned}
$$

where $a_{s+1}(k, m, d, \bar{e}, z) \equiv k_{s+1}(k, m, d, \bar{e}, z)+m_{s+1}(k, m, d, \bar{e}, z)+d_{s+1}(k, m, d, \bar{e}, z)$.

2. Relative prices $\{w, r\}$ solve the firm's optimization problem by satisfying (11) and (10).

3. Given relative prices $\{w, r\}$ and government policy $\left\{\tau_{r}, \tau_{w}, \theta, b(), G,. t r, \mu\right\}$, individual policy rules $c_{s}(\cdot), k_{s+1}(\cdot), m_{s+1}(\cdot)$, and $d_{s+1}(\cdot)$ solve the consumer's dynamic program (17).

4. The government budget (15) is balanced.

5. Social security benefits equal taxes:

$$
\theta w N=\text { Pens }:=\sum_{s=R}^{T} \int_{k} \int_{m} \int_{d} \int_{\bar{e}} \int_{z} b(\bar{e}, j) \varphi_{s}(k, m, d, \bar{e}, z) d z d \bar{e} d d d m d k
$$

6. Money grows at the exogenous rate $\mu$.

7. The goods market clears:

$$
K^{\alpha} N^{1-\alpha}=C+G+\delta K+T C
$$


In particular, transaction costs in the case 2 are a social cost:

$$
T C=\sum_{s=1}^{T} \int_{k} \int_{m} \int_{\bar{e}} \int_{z}\left(\int_{0}^{\zeta(k, m \bar{e}, z)} w \kappa\left(c_{s}(k, m, \bar{e}, z), i\right) d i\right) \varphi_{s}(k, m, \bar{e}, z) d z d \bar{e} d m d k .
$$

\section{Calibration}

Periods correspond to years. We assume that agents are born at the real lifetime age 20 which corresponds to $s=1$. Agents work $R-1=40$ years corresponding to a real lifetime age of 60 . They live a maximum life of 60 years $(T=60)$ so that agents do not become older than the real lifetime age 79 . The sequence of conditional survival probabilities $\left\{\phi_{s}\right\}_{s=1}^{59}$ is set in accordance with the age-specific death rates in the US in the year 2000. The data is taken from the United States Life Tables 2000 provided by the National Center of Health. ${ }^{10}$ The survival probabilities almost monotonously decrease with age. For the final period of our model, we set the survival probability $\phi_{60}$ equal to zero.

The calibration of the production parameters $\alpha$ and $\delta$ and the Markov process $e\left(s, z_{h}\right)$ is chosen in accordance with existing general equilibrium studies: Following Prescott (1986), the capital income share $\alpha$ is set equal to 0.36 . The annual rate of depreciation is set at $\delta=0.08$. Earnings are the product of real wage per efficiency unit times the labor endowment $e\left(s, z_{h}\right)$. The labor endowment process is given by $e\left(s, z_{h}\right)=e^{z_{h}+\bar{y}_{s}}$, where $\bar{y}_{s}$ is the mean lognormal income of the $s$-year old. The mean efficiency index $\bar{y}_{s}$ of the $s$-year-old worker is taken from Hansen (1993) and interpolated to in-between years. As a consequence, we are able to replicate the cross-section age distribution of earnings of the US economy. We also normalize the average efficiency index to one. The age-productivity profile is hump-shaped and earnings peak at age 50. Agents differ in log labor endowments at birth and there is no income mobility within an age cohort so that $z_{h}$ is constant for all $s=1, \ldots, R-1$. We follow Huggett (1996) and choose a lognormal distribution of earnings for the 20-year old with $\sigma_{y_{1}}=0.38$ and mean $\bar{y}_{1}$. As the log endowment of the initial generation of agents is normally distributed, the log efficiency of subsequent agents will continue to be normally distributed. This is a useful property of the earnings

\footnotetext{
${ }^{10}$ See Table 1 in Arias (2002).
} 
process, which has often been described as lognormal in the literature. With our earnings specification, we come close to the earnings heterogeneity that is observed in US data. Henle and Ryscavage (1980) compute an earnings Gini coefficient for men of 0.42 in the period 1958-77. In our model the Gini coefficient is 0.36 .

The social security payment $b\left(s, \bar{e}_{h}\right)$ is calibrated and parameterized in order to match the US Social Security System and exactly follows Huggett and Ventura (2000). ${ }^{11}$ Average earnings $\bar{e}_{s, t}$ of the $s$-year old in period $t$ accumulate according to:

$$
\bar{e}_{s, t}= \begin{cases}\left(\bar{e}_{s-1, t-1}(j-1)+\min \left\{e\left(s, z_{h t}\right) w_{t}, e_{\max }\right\}\right) / j & \text { for } s<R-1 \\ \bar{e}_{s-1, t-1} & \text { else. }\end{cases}
$$

We note that in the US benefits depend on mean earnings that are indexed so that later contributions in life are not discounted. Furthermore, average earnings are only calculated for up to some maximum earnings level $e_{\max }$ which amounts to 2.47 times average earnings $\bar{E} .^{12}$

Following Huggett and Ventura, we set the lump-sum benefit $b_{0}$ equal to $12.42 \%$ of GDP per capita in the model economy. Finally, benefits are regressive and a concave function of average earnings. Let $\bar{e}_{h}$ and $\bar{E}$ denote the average earnings of individual $h$ and the average earnings of all workers, respectively. Depending on which earnings bracket the retired agent's average earnings $\bar{e}_{h}$ were situated, he received $90 \%$ of the first $20 \% \cdot \bar{E}, 32 \%$ of the next $104 \%$ of $\bar{E}$, and $15 \%$ of the remaining earnings $\left(\bar{e}_{h}-1.24 \bar{E}\right)$ in 1994 . Therefore, the marginal benefit rate declines with average earnings. The social security contribution rate $\theta$ is calibrated so that the budget of the social security balances. The remaining parameters of the government policy that we need to calibrate are the two tax rates $\tau_{r}$ and $\tau_{w}$ and government expenditures $G$. The two tax rates $\tau_{r}=42.9 \%$ and $\tau_{w}=24.8 \%$ are computed as the average values of the effective US tax rates over the time period 1965-88 that are reported by Mendoza, Razin, and Tesar (1994). The share of government consumption in GDP is $G / Y=19.5 \%$, which is equal to the average ratio of $\mathrm{G} / \mathrm{Y}$ in the US during 1959-93 according to the Economic Report of the President (1994). The model parameters are presented in Table 3.

\footnotetext{
${ }^{11}$ For a more detailed description of this procedure please see Huggett and Ventura (2000).

${ }^{12}$ In the US Social Security System, only the 35 highest earnings payments are considered in the calculation of the average earnings. We simplify the analysis by using all 40 working years in our model.
} 
Table 3: Calibration of parameter values for the US economy

\begin{tabular}{|c|c|c|}
\hline Description & Function/Parameter & Parameter Value \\
\hline utility function & $U=\frac{\left(c^{\gamma} m^{1-\gamma}\right)^{1-\sigma}}{1-\sigma}$ & $\begin{array}{l}\sigma=2.0 \\
\gamma=0.9787(\text { case } 1) \\
\gamma=1(\text { cases } 2 \text { and } 3)\end{array}$ \\
\hline discount factor & $\beta$ & $\beta=1.011$ \\
\hline production function & $Y=K^{\alpha} N^{1-\alpha}$ & $\alpha=0.36$ \\
\hline depreciation & $\delta$ & $\delta=0.08$ \\
\hline financial services & $\kappa_{0}\left(\frac{i}{1-i}\right)^{\chi}+\frac{\kappa_{1}}{c(i)}$ & $\begin{array}{l}\kappa_{0}=0.154, \chi=0.3232 \\
\kappa_{1}=0\end{array}$ \\
\hline money growth rate & $\mu$ & $\mu=0.0432$ \\
\hline income tax rates & $\tau_{r}, \tau_{w}$ & $\tau_{r}=42.9 \%, \tau_{w}=24.8 \%$ \\
\hline government consumption & $G$ & $G / Y=19.5 \%$ \\
\hline social security benefits & & \\
\hline $\begin{array}{l}\text { maximum earnings level } \\
\text { lump-sum benefit }\end{array}$ & $\begin{array}{l}e_{\max } \\
b_{0}\end{array}$ & $\begin{array}{l}e_{\max }=2.47 E \\
b_{0}=0.1241 Y\end{array}$ \\
\hline$b_{1}(\bar{\epsilon})$ & earnings bracket & marginal benefit rate \\
\hline & {$[0,0.2 \bar{E}]$} & 0.90 \\
\hline & $(0.2 \bar{E}, 1.24 \bar{E}]$ & 0.32 \\
\hline & $1.24 \bar{E}<\bar{e} \leq e_{\max }$ & 0.15 \\
\hline
\end{tabular}


We choose the coefficient of risk aversion $\sigma=2 .{ }^{13}$ The discount factor $\beta=1.011$ is set equal to the estimate of Hurd (1989). In case 1, the remaining parameter $\gamma$ from the utility function is chosen to match the average velocity of money $P Y / M$. During 1960-2001, the average annual velocity of M1 amounted to 6.0, while the average inflation rate was equal to $4.32 \%$. We set $\gamma=0.9787$ implying a velocity of money in our benchmark model without productivity mobility equal to 6.0 (for $\pi=4.32 \%$ ). The initial endowment with money is chosen so that $\bar{M}_{h 0} / P_{t}$ is close to $\bar{M}_{h 2} / P_{t}$, the optimal stock of money accumulated by the $s=1$ year old households for their next period of life $s=2$. In case 2, we follow Erosa and Ventura (2002) and choose the parameters $\kappa_{0}$ and $\chi$ so that $82 \%$ of all household transactions are made with cash. As in Erosa and Ventura (2002) we set $\chi=0.3232$. In our benchmark case $\kappa_{1}=0$ and $\kappa_{0}=0.154$ imply a cash share equal to $82 \%$.

The computation of the model is briefly described in the Appendix.

\section{Findings}

Figures 3, 4, and 5 display the age profile of assets (capital and money balances), consumption, and gross income generated by the money in the utility function model (MIUF for further reference), the costly credit model (CC), and the limited participation model $(\mathrm{LP})$.

The consumption smoothing behavior is clearly discernible and common to all three models. Irrespective of the level of income - as governed by the exogenously specified time paths of productivity - the time path of consumption is hump-shaped, despite the sudden decline of gross income taking place at the age of retirement (see the lower left and lower right panels of Figures 3, 4, and 5). Corresponding to the time path of consumption is the hump-shaped time path of interest bearing assets (capital in the MIUF and CC models, capital and bank deposits in the LP model) for the richer households $(j=3,4,5)$.

The upper right panels of Figures 3, 4, and 5 reveal the consequences of the different motives to store money on the time profile of real money holdings. In the MIUF model, real money holdings are proportional to consumption and, thus, their time profile is also hump-shaped. In the CC model this only holds for the poorer households $j=1,2,3$.

\footnotetext{
${ }^{13}$ All our qualitative results also hold for the case $\sigma \in\{1,4\}$.
} 
Figure 3: Assets, Consumption, and Gross Income in the MIUF Model
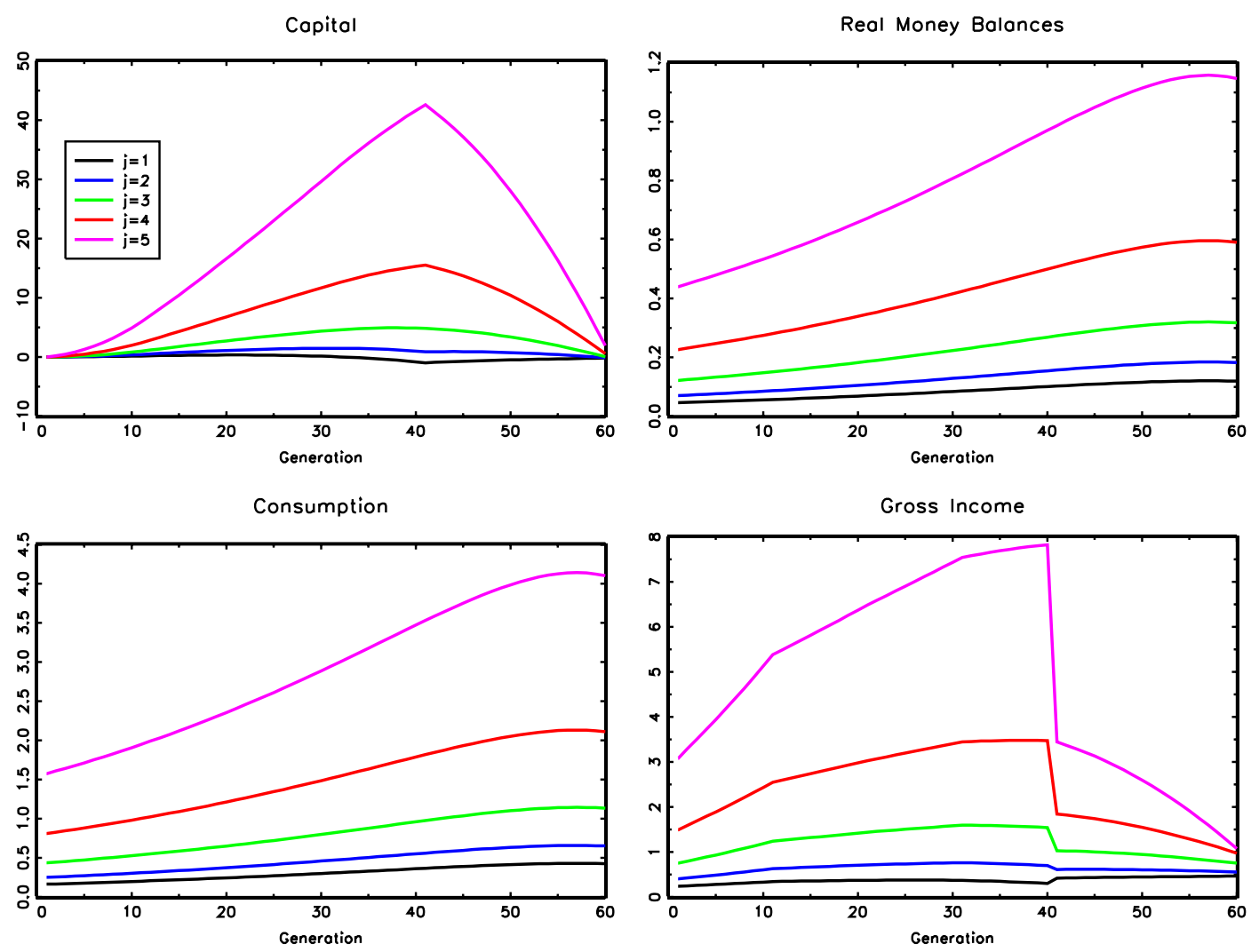

Richer households can afford higher credit costs and, thus, reduce their money holdings. In the LP model the time profile of money balances is the mirror image of the time profile of gross income. In oder to sustain consumption, households must build up considerable money balances at the age of retirement. Households that receive high wage income save part of this income. The cash-in-advance constraint does not bind for this group in their youth, and, consequently, they do not hold any cash balances.

Table 4 presents the correlations between money holdings, gross income, and interest bearing assets implied by the three different models. The LP model comes close to reproduce the low correlation between income and money as well as between money and interest bearing assets found in the data (see Table 1). Yet, as the other two models it predicts a much to strong association between gross income and interest bearing assets.

Figures 6,7 , and 8 shed light on the intra-generational distribution of money holdings. 
Figure 4: Assets, Consumption, and Gross Income in the CC Model
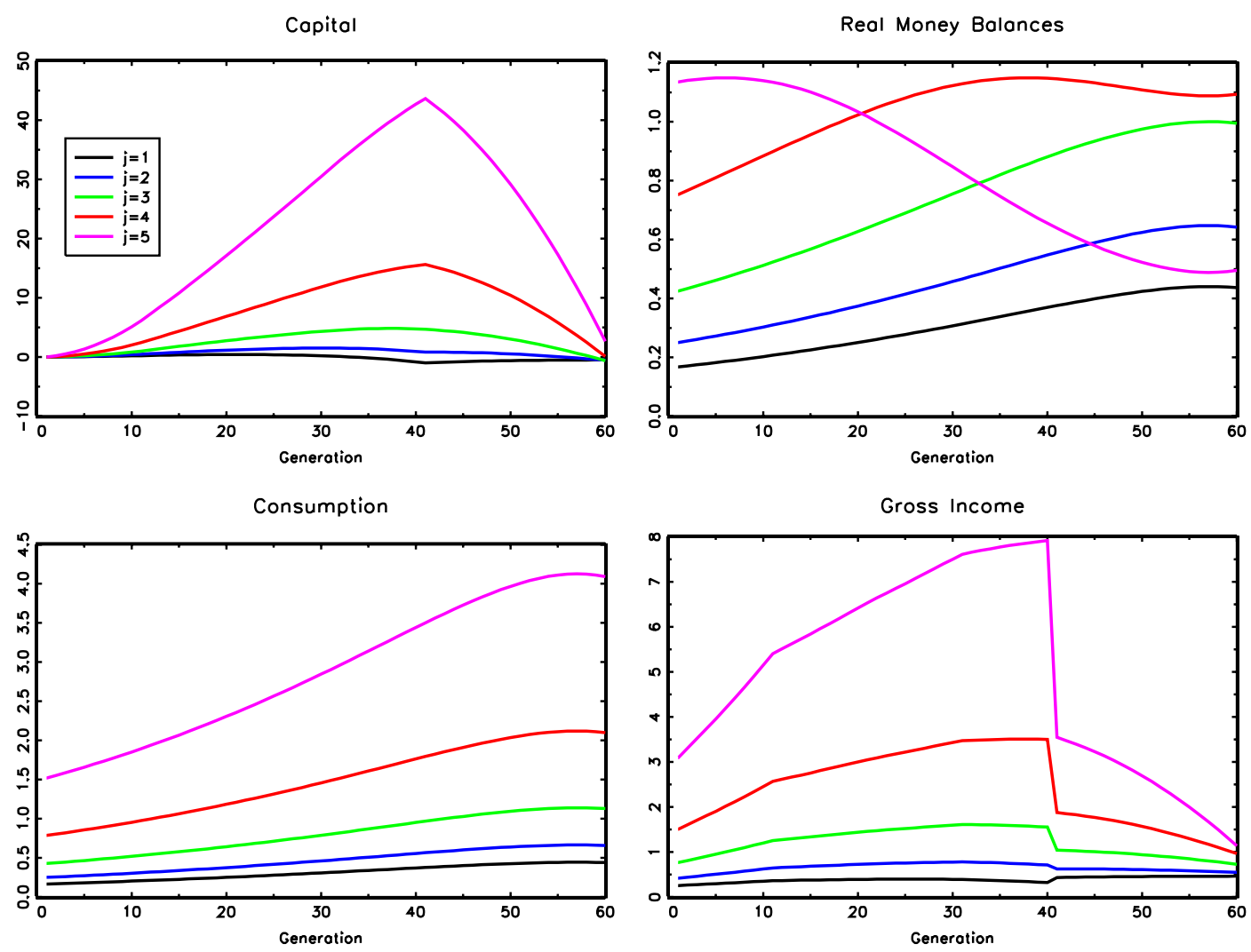

With respect to average money holdings all three models replicate the hump-shaped profile found in the data (see the upper left panels in Figures 6, 7, 8, and 2, respectively). The $\mathrm{CC}$ model is consistent with the declining variational coefficient of money holdings that we find in the PSID 1994 data set (see the lower left panels of Figures 9 and 8). The more irregular patterns observed in the PSID-1999 and PSID-2001 data sets are better explained with the LP model.

The overall association between money holdings, gross income, interest bearing assets, and age predicted by our three models is much stronger than we observe for US-households. Table 5 displays the results obtained from regressions of our model data. The multiple correlation coefficient $R^{2}$ obtained from all three models is four to five times larger than the empirical magnitudes shown in Table 2. Both the MIUF and the CC model predict the empirically observed sign of the coefficients on income and age. In addition, the CC model 
Table 4: Correlations implied by our models

\begin{tabular}{lccc}
\hline \hline Model & money/income & money/capital & capital/income \\
\hline MIUF & 0.67 & 0.84 & 0.77 \\
CC & 0.56 & 0.49 & 0.75 \\
LP & 0.09 & 0.43 & 0.83 \\
\hline
\end{tabular}

Table 5: Regressions with model data

\begin{tabular}{lcccccccc}
\hline \hline Model & constant & income & income $^{2}$ & capital & capital $^{2}$ & age & age $^{2}$ & $R^{2}$ \\
\hline MIUF & 0.15 & 0.10 & -0.01 & 0.03 & -0.00 & -0.02 & 0.00 & 0.88 \\
& $(6.64)$ & $(7.77)$ & $(-8.84)$ & $(8.81)$ & $(-4.69)$ & $(-8.20)$ & $(8.71)$ & \\
CC & 0.01 & 0.44 & -0.04 & -0.01 & -0.00 & 0.01 & 0.00 & 0.80 \\
& $(0.562)$ & $(27.0)$ & $(-28.53)$ & $(-1.38)$ & $(-1.74)$ & $(2.02)$ & $(1.25)$ & \\
LP & 0.29 & 0.13 & -0.07 & 0.11 & -0.00 & -0.05 & 0.00 & 0.75 \\
& $(3.53)$ & $(1.84)$ & $(-9.88)$ & $(5.47)$ & $(-1.31)$ & $(-7.30)$ & $(8.07)$ & \\
\hline
\end{tabular}

Notes: Robust $t$-ratios in parenthesis 
Figure 5: Assets, Consumption, and Gross Income in the LP Model
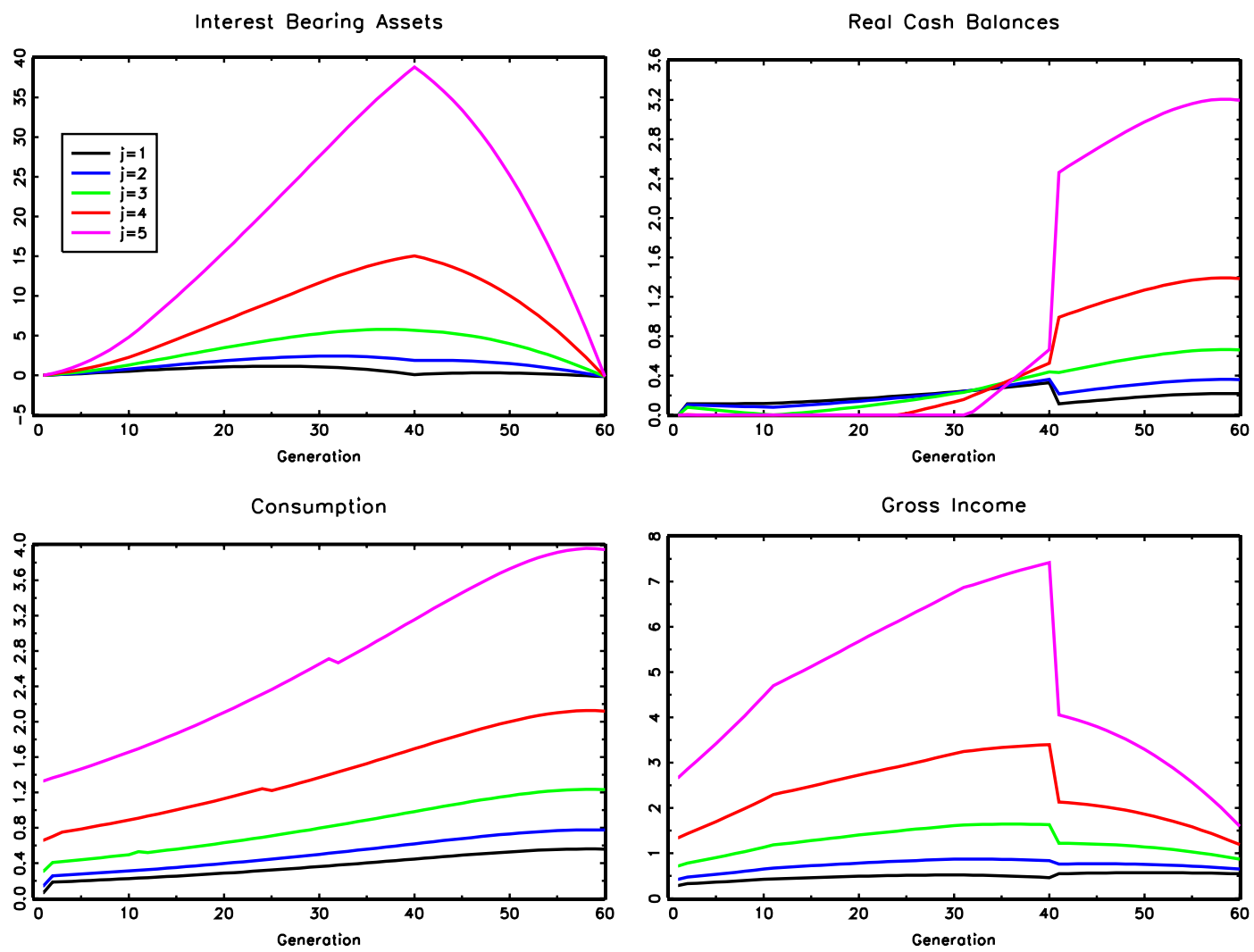

is consistent with the insignificant coefficients on capital observed in our regressions.

\section{Conclusion}

When we extend the familiar infinitely-lived representative economy with money-in-theutility, costly credit or limited participation approches to money in the overlapping-generations model with heterogeneous productivity types, we encounter many counterfactual implications for the money-age and cross-sectional money distribution. None of these economies with either of the three money demand motives can reconcile its implications for the money distribution with the empirical facts with regard to the dispersion of money holdings and the cross-section correlation of money with income and wealth. We conclude that our knowledge of the cross-section distribution of money is limited, even with limited partici- 
Figure 6: Distribution of Money in the MIUF Model
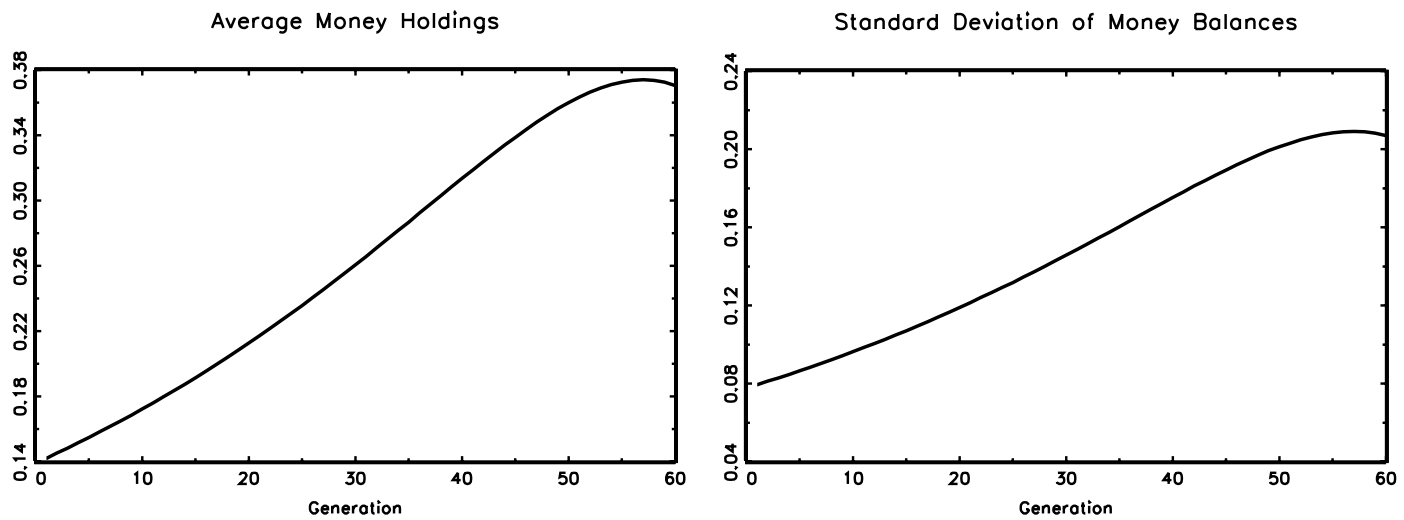

Voriational Coefficient of Money Balances

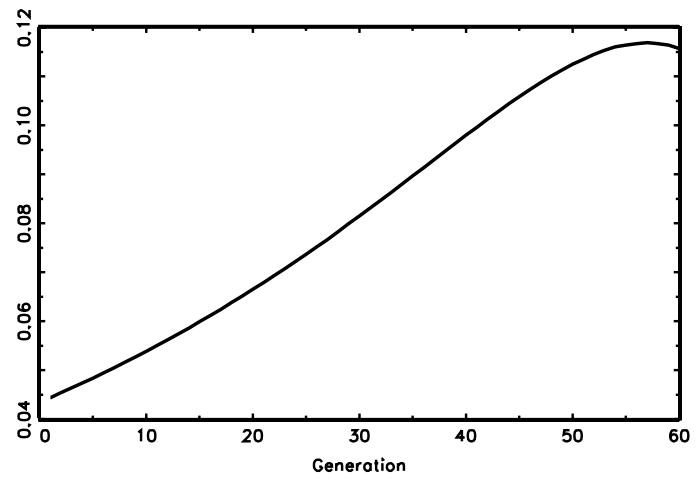

pation models. Newer approaches are needed to explain the dispersion of money holdings over the life-cycle. 
Figure 7: Distribution of Money in the CC Model
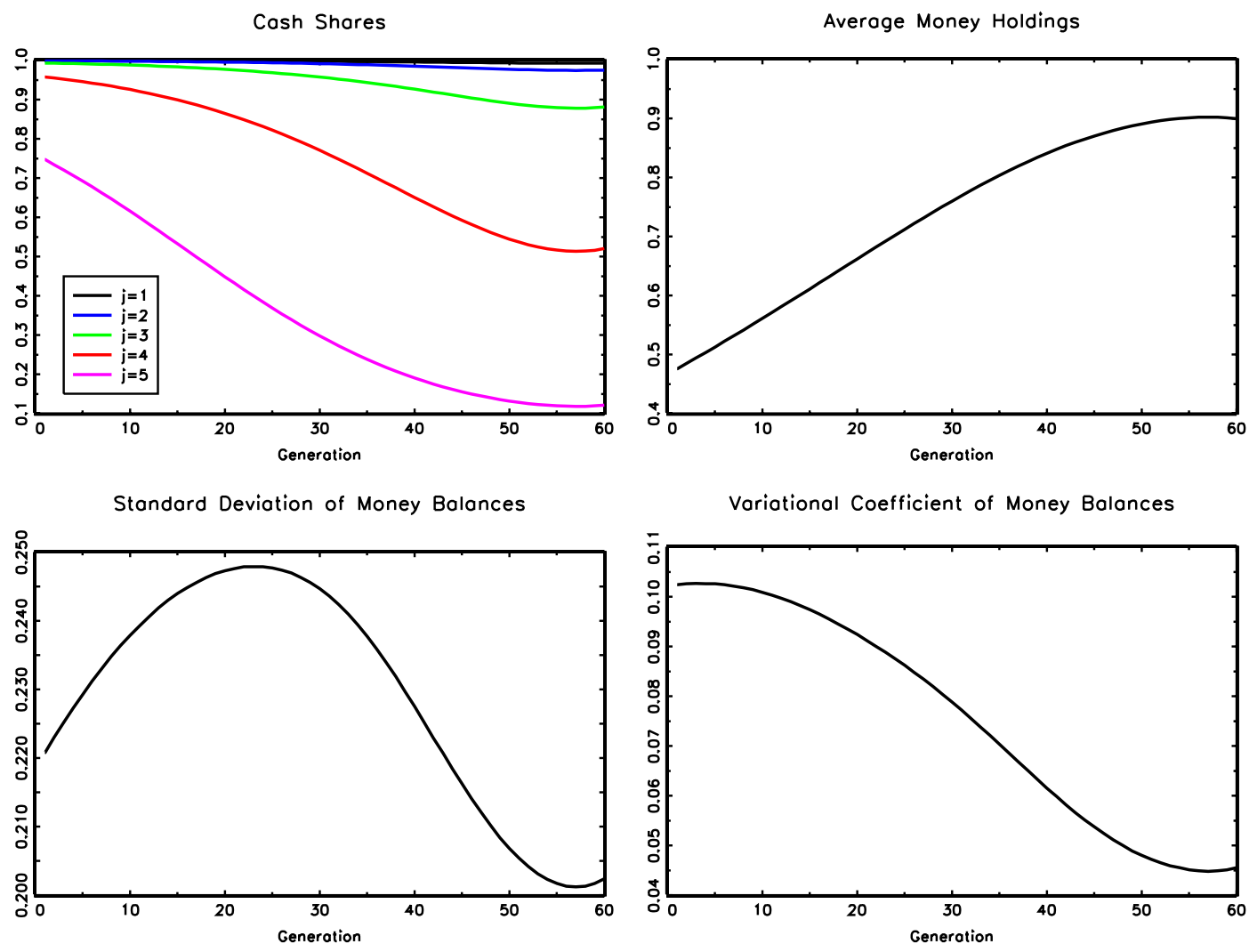
Figure 8: Distribution of Cash in the LP Model
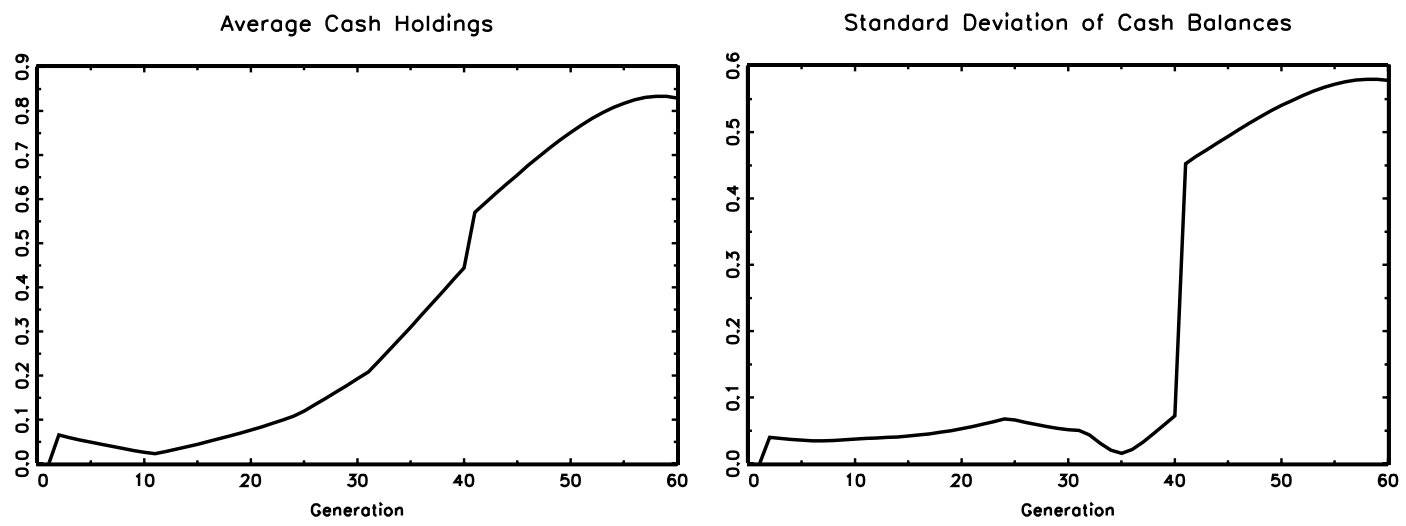

Variational Coefficient of Cash Balances

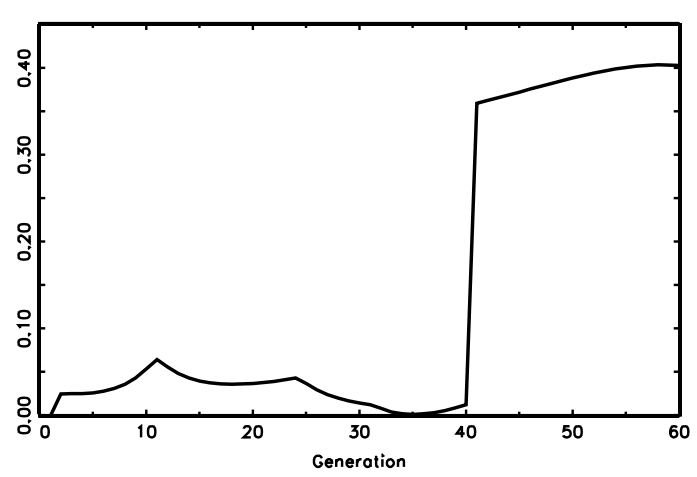




\section{References}

Arias, E., 2002, United States Life Tables 2000, National Vital Statistics, vol. 51, 1-38.

Attanasio, O.P., L. Guiso, and T. Jappelli, 2002, The demand for money, financial innovation, and the welfare cost of inflation: An analysis with household data, Journal of Political Economy, vol. 110, 317-351.

Bhattarcharya, J., J. Haslag, and S. Russelll, 2005, the role of moneyin two alternative models: When is the Friedman Rule optimal and why?, Journal of Monetary Economics,

Díaz-Giménez, J., V. Quadrini, and J.V. Ríos-Rull, 1997, Dimensions of Inequality: Facts on the U.S. Distributions of Earnings, Income, and Wealth, Federal Reserve Bank of Minneapolis Quarterly Review 21, 3-21.

Dotsey, M., and P. Ireland, 1996, The welfare cost of inflation in general equilibrium, Journal of Monetary Economics, vol. 37, 29-47.

Erosa, A., and G. Ventura, 2002, On inflation as a regressive consumption tax, Journal of Monetary Economics, vol. 49, 761-95.

Freeman, S., 1987, Reserve requirements and optimal seigniorages, Journal of Monetary Economics, vol. 19, 307-14.

Gillman, M., 1993, The welfare costs of inflation in cash-in-advance economies with costly credit, Journal of Monetary Economics, vol. 31, 97-115.

Gomes, F., and A. Michaelides, 2005, Optimal Life Cycle Asset Allocation: Understanding the Evidence, The Journal of Finance, forthcoming.

Hansen, G., 1993, The cyclical and secular behavior of the labor input: comparing efficiency units and hours worked, Journal of Applied Econometrics 8, 71-80.

Heer, B., and A. Maußner, 2005, Dynamic General Equilibrium Modelling: Computational Methods and Applications, Springer: Berlin. 
Heer, B., and B. Süssmuth, 2007, Effects of Inflation on Wealth Distribution: Do stock market participation fees and capital income taxation matter?, Journal of Economic Dynamics and Control, 31, $277-301$.

Henle, P., and P. Ryscavage, 1980, The distribution of earned income among men and women 1958-77, Monthly Labor Review, April, 3-10.

Huggett, M., 1996, Wealth distribution in Life-Cycle Economies, Journal of Monetary Economics, vol. 17, 953-69.

Huggett, M., and G. Ventura, 2000, Understanding why income households save more than low income households, Journal of Monetary Economics, vol. 45, 361-97.

Hurd, M., 1989, Mortality risk and bequests, Econometrica, vol. 57, 779-813.

Mendoza, E.G., A. Razin, and L.L. Tesar, 1994, Effective tax rates in macroeconomics: Cross country stimates of tax rates on factor incomes and consumption, Journal of Monetary Economics, vol. 34, 297-323.

Prescott, E., 1986, Theory Ahead of Business Cycle Measurement, Federal Reserve Bank of Minneapolis Quarterly Review, vol. 10, 9-22.

Schreft, S., 1992, Transaction costs and the use of cash and credit, Economic Theory, vol. 2, 283-94.

Stokey, N., J.R. Lucas, and E.C. Prescott, 1989, Recursive methods in economic dynamics, Harvard University Press, Cambridge, Ma.

Storesletten, K. Ch. I. Telmer, and A. Yaron, 2004, Consumption and Risk Sharing over the Life Cycle, Journal of Monetary Economics, vol. 51, 609-633

Tauchen, G., 1986, Finite State Markov-Chain Approximations To Univariate and Vector Autoregressions, Economics Letters, vol. 20, 177-81. 


\section{Appendix}

In this Appendix we provide empirical evidence on the individual data sets and detail the computation of our three models.

\subsection{Analysis of the 1994, 1999, and 2001 PSID-data sets}

Figures 9 through 11 display the relation between money holdings and age. The blue lines are cubic polynomials fitted to the data to highlight possible trends.

Figure 9: Cash holdings over the life-cycle: 1994-data
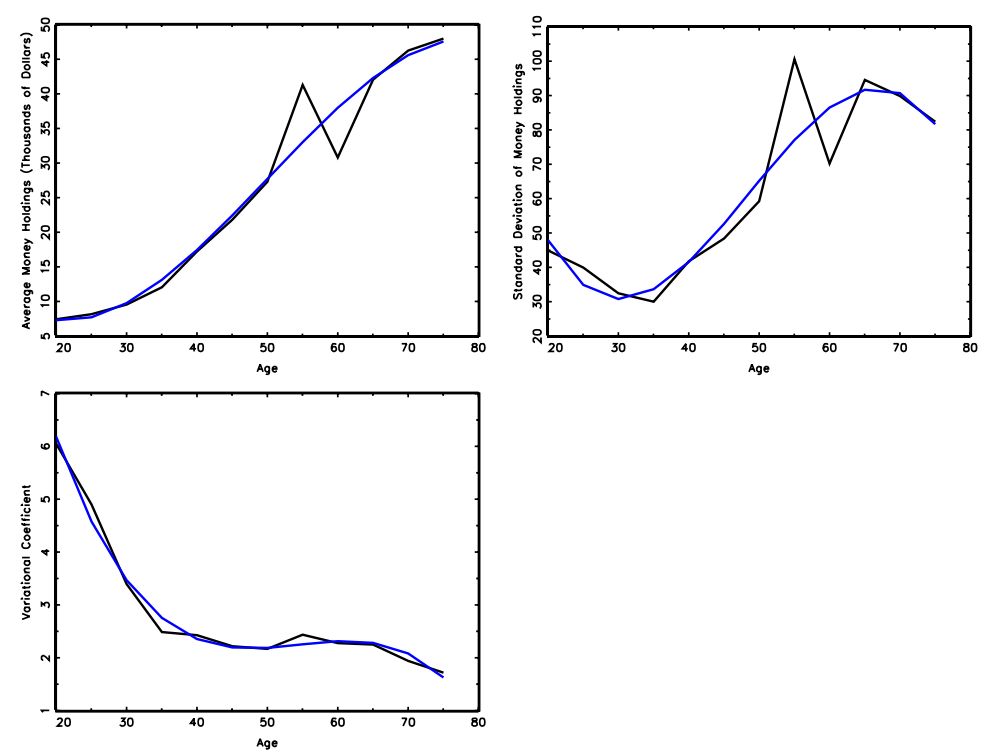
Figure 10: Cash holdings over the life-cycle: 1999-data
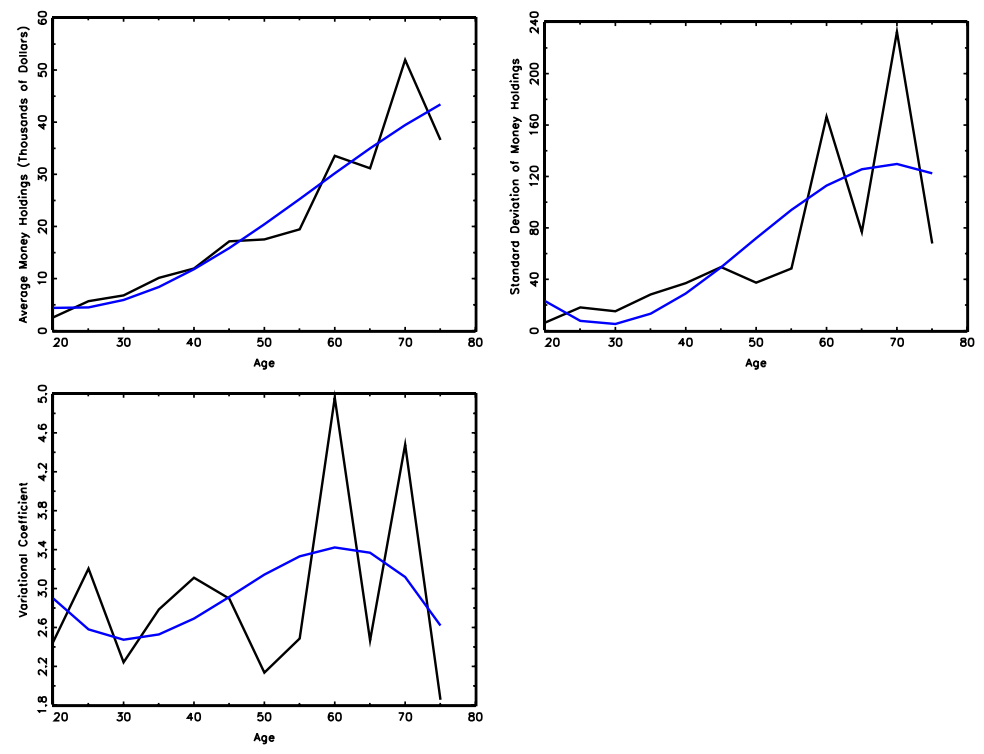

Figure 11: Cash holdings over the life-cycle: 2001-data
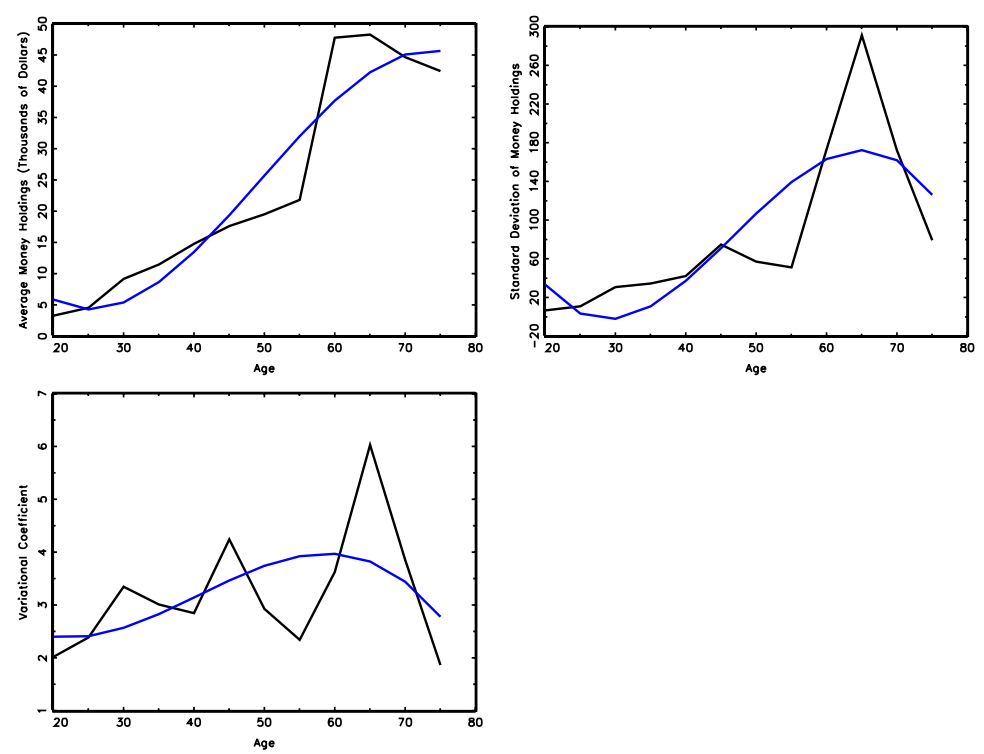
Table 6 displays the regression results using the individual data sets.

Table 6: Regressions of money holdings on income, wealth, and age

\begin{tabular}{ccccccccc}
\hline \hline Year & constant & income & income $^{2}$ & capital & capital $^{2}$ & age & age $^{2}$ & $R^{2}$ \\
\hline 1994 & 8.38 & 0.20 & -0.00 & 0.12 & -0.00 & -0.73 & 0.01 & 0.13 \\
& $(1.17)$ & $(3.25)$ & $(-1.07)$ & $(4.10)$ & $(-4.19)$ & $(-1.85)$ & $(3.47)$ & \\
1999 & 30.25 & 0.42 & -0.00 & -0.01 & 0.00 & -2.48 & 0.03 & 0.14 \\
& $(2.56)$ & $(3.38)$ & $(-3.56)$ & $(-0.44)$ & $(1.98)$ & $(-2.78)$ & $(3.24)$ & \\
2001 & 23.74 & 0.33 & -0.00 & 0.00 & 0.00 & -2.05 & 0.03 & 0.16 \\
& $(2.65)$ & $(4.83)$ & $(-0.37)$ & $(0.14)$ & $(2.39)$ & $(-3.38)$ & $(3.99)$ & \\
\hline
\end{tabular}

Notes: Robust $t$-ratios in parenthesis

\subsection{Individual productivity and aggregate labor}

Let $\bar{y}_{s}$ denote the mean efficiency index of the $s$-year old worker. We approximate the productivity distribution among the members of generation $s=1$ by the distribution of earnings for the 20-year old used by Huggett (1996). We discretize his distribution at $l=5$ points $y_{h 1}, h=1,2, \ldots, l$. Since there is no income mobility, we are able to index households with the index $h$. Thus, the productivity of household $h$ at age $s$ is given by $e_{s} z_{h}$, where $e_{s}=e^{\bar{y}_{s}}$ and $z_{h}=e^{y_{h 1}}$. Let $\psi_{s}$ denote the mass of generation $s$. We normalize the total mass of all generations to one, $\sum_{s=1}^{T} \psi_{s} \equiv 1$. Note that

$$
\psi_{s+1}=\phi_{s} \psi_{s}
$$

We use $\nu_{h}, \sum_{h=1}^{l} \nu_{h} \equiv 1$ to denote the mass the mass of households with productivity $z_{h}$. Since individual labor supply is exogenous and equal to $n_{h s}=1$ for all $h=1, \ldots, l$ and $s=1,2, \ldots R-1$, aggregate effective labor input $N$ equals

$$
N=\sum_{s=1}^{T} \sum_{h=1}^{l} \psi_{s} \nu_{h} e_{s} z_{h} .
$$

Given the aggregate wage rate $w$, which is a constant in the stationary equilibrium of the model, we are able to compute the social security benefits of retired households. These benefits depend on the household's productivity parameter $z_{h}$ but not on his age:

$$
b_{h s}= \begin{cases}0 & \text { for } s=1,2, \ldots, R-1, \\ \bar{b}_{h}>0 & \text { for } s=R, R+1, \ldots, T .\end{cases}
$$


This allows us to calibrate the social security tax rate $\theta$ from the knowledge of $w$ alone:

$$
\theta=\frac{\text { Pens }}{\tau_{w} N}, \quad \text { Pens }=\sum_{s=R}^{T} \sum_{h=1}^{l} \psi_{s} \nu_{h} \bar{b}_{h} .
$$

\subsection{Money in the utility function}

First order conditions. In the stationary solution the wage rate $w$, the real interest rate $r$, the inflation factor $\pi=1+\mu$, household labor supply $n \equiv 1$, government transfers $t r$, and social security payments $b_{h}$ are independent of calendar time and exogenously given to household $h \in\{1,2, \ldots l\}$. Since transfers are distributed lump sum and since the mass of all agents is one, aggregate equal individual transfers. The Lagrangian of the household's decision problem at age $s=1$ is given by

$$
\begin{aligned}
\mathscr{L}= & \sum_{s=1}^{T} \beta^{s-1} \prod_{j=1}^{s} \phi_{j} \frac{c_{h s}^{\gamma(1-\sigma)} m_{h s}^{(1-\gamma)(1-\sigma)}}{1-\sigma} \\
+ & +\sum_{s=1}^{R-1} \beta^{s-1} \prod_{j=1}^{s} \phi_{j} \lambda_{h s}\left[\left(1-\tau_{w}-\theta\right) w e_{s} z_{h}+\left(1-\left(1-\tau_{r}\right) r\right) k_{h s}\right. \\
& \left.+t r+m_{h s}-c_{h s}-\pi m_{h s+1}-k_{h s+1}\right] \\
& +\sum_{s=R}^{T} \beta^{s-1} \prod_{j=1}^{s} \phi_{j} \lambda_{h s}\left[\bar{b}_{h}+\left(1-\left(1-\tau_{r}\right) r\right) k_{h s}+t r+m_{h s}-c_{h s}-\pi m_{h s+1}-k_{h s+1}\right] .
\end{aligned}
$$

The first-oder conditions with respect to $c_{h s}, k_{h s+1}$, and $m_{h s+1}$ are:

$$
\begin{aligned}
\frac{\partial \mathscr{L}}{\partial c_{h s}} & =\beta^{s-1} \prod_{j=1}^{s} \phi_{j}\left[\gamma c_{h s}^{\gamma(1-\sigma)-1} m_{h s}^{(1-\gamma)(1-\sigma)}-\lambda_{h s}\right]=0, \\
\frac{\partial \mathscr{L}}{\partial k_{h s+1}} & =\beta^{s-1} \prod_{j=1}^{s} \phi_{j}\left[-\lambda_{h s}+\beta \phi_{s+1} \lambda_{h s+1}\left(1+\left(1-\tau_{r}\right) r\right)\right]=0, \\
\frac{\partial \mathscr{L}}{\partial m_{h s+1}} & =\beta^{s-1} \prod_{j=1}^{s} \phi_{j}\left[-\pi \lambda_{h s}+\beta \phi_{s+1}\left((1-\gamma) c_{h s+1}^{\gamma(1-\sigma)} m_{h s+1}^{(1-\gamma)(1-\sigma)-1}+\lambda_{h s+1}\right)\right]=0 .
\end{aligned}
$$


These three equations can be reduced to

$$
\begin{aligned}
m_{h s+1} & =\frac{(1-\gamma) / \gamma}{\pi\left(1+\left(1-\tau_{r}\right) r\right)-1} c_{h s+1}, \\
1 & =\beta \phi_{s+1}\left(\frac{c_{h s+1}}{c_{h s}}\right)^{\gamma(1-\sigma)-1}\left(\frac{m_{h s+1}}{m_{h s}}\right)^{(1-\gamma)(1-\sigma)}\left(1+\left(1-\tau_{r}\right) r\right) .
\end{aligned}
$$

Together with the household's budget constraint

$$
c_{h s}=\left(1-\tau_{w}-\theta\right) w e_{s} z_{h}+b_{h s}+\left(1+\left(1-\tau_{r}\right) r\right) k_{h s}+t r+m_{h s}-\pi m_{h s+1}-k_{h s+1}
$$

they form a system in $2(T-1)+T$ equations in the unknowns $c_{h s}, s=1, \ldots, T, k_{h s+1}$, and $m_{h s+1}, s=1, \ldots, T-1$.

Computational strategy. Suppose we are given individual capital stocks $k_{h s}^{0}$ and real money holdings $m_{h s}^{0}, h=1,2, \ldots, l, s=2, \ldots, T$ as well as money transfers from the government to the newborn $m_{h 1}, h=1, \ldots, l$. We compute new values in the following steps:

Step 1: $N$ is given from (22). The aggregate stock of capital is

$$
K=\sum_{s=2}^{T} \sum_{h=1}^{l} \psi_{s} \nu_{h} k_{h s}
$$

This allows us to compute the average wage rate $w$ and the real interest rate $r$ via equations (10) and (11). Furthermore, aggregate output is

$$
Y=N^{1-\alpha} K^{\alpha}
$$

so that government's purchases of goods equal $G=0.195 Y$.

Step 2: Given $w$, equation (24) delivers $\theta$ and equations (21) imply $\bar{b}_{h}$.

Step 3: We compute government transfers. Before we are able to do so, we need to know seignorage and aggregate bequests. The latter are given by

$$
B e q=\sum_{s=1}^{T-1}\left(1-\phi_{s+1}\right) \psi_{s} \sum_{h=1}^{l} \nu_{h}\left(k_{h s+1}+\pi m_{h s+1}\right),
$$

and the former by

$$
\text { Seign }=(\pi-1) \sum_{s=2}^{T} \sum_{h=1}^{l} \psi_{s} \nu_{h} m_{h s} .
$$


Thus, the government's budget constraint implies

$$
t r=\tau_{r} r K+B e q+\operatorname{Sein}-G-\psi_{1} \sum_{h=1}^{l} \nu_{h} m_{h 1} .
$$

Step 4: Given this information we can solve equations (26) for new values of $k_{h s+1}$ and $m_{h s+1}$. The fixed point of this mapping is the solution to our model.

We supply starting values for a non-linear equations solver from a simpler model without money. The individual capital stocks in this model can be found from solving a system of linear equations. We use individual consumption implied by this solution and equation (26a) to compute $m_{h 1}$ and to initialize $m_{h s+1}$.

\subsection{Costly credit}

First order conditions. The credit costs of household $h$ are given by

$$
T C_{h s}\left(\zeta_{h s}\right)=\int_{0}^{\zeta_{h s}}\left[\kappa_{0}\left(\frac{i}{1-i}\right)^{\chi}+\frac{\kappa_{1}}{c_{h s}(i)}\right] d i .
$$

The derivation of this function with respect to $\zeta_{h s}$ is:

$$
T C_{h s}^{\prime}\left(\zeta_{h s}\right)=\kappa_{0}\left(\frac{\zeta_{h s}}{1-\zeta_{h s}}\right)^{\chi}+\frac{\kappa_{1}}{c_{h s}\left(\zeta_{h s}\right)} .
$$

It is obvious from the specification of (32) that the agent will never choose $\zeta_{h s}=1$. Therefore, we need only consider the case $\zeta_{h s} \in[0,1)$. The Lagrangian of the household is

$$
\begin{aligned}
\mathscr{L}_{h}= & \sum_{s=1}^{T} \beta^{s-1} \prod_{j=1}^{s} \phi_{j} \frac{c_{h s}^{1-\sigma}}{1-\sigma} \\
+ & \sum_{s=1}^{R-1} \beta^{s-1} \prod_{j=1}^{s} \phi_{j} \lambda_{h s}\left[\left(1-\tau_{w}-\theta\right) e_{s} z_{h} w+\left(1+\left(1-\tau_{r}\right) r\right) k_{h s}+t r+m_{h s}\right. \\
& \left.\quad-w T C_{h s}\left(\zeta_{h s}\right)-c_{h s}-k_{h s+1}-\pi m_{h s+1}\right] \\
+ & \sum_{s=R}^{T} \beta^{s-1} \prod_{j=1}^{s} \phi_{j} \lambda_{h s}\left[\bar{b}_{h}+\left(1+\left(1-\tau_{r}\right) r\right) k_{h s}+t r+m_{h s}\right. \\
+ & \left.\quad-w T C_{h s}\left(\zeta_{h s}\right)-c_{h s}-k_{h s+1}-\pi m_{h s+1}\right] \\
+ & \sum_{s=R}^{T} \beta^{s-1} \prod_{j=1}^{s} \phi_{j}\left[\Gamma_{h s}\left(m_{h s}-\left(1-\zeta_{h s}\right) c_{h s}\right)+\Psi_{h s} \zeta_{h s}\right] .
\end{aligned}
$$


The first-order conditions with respect to the share of credit-goods are:

$$
\begin{aligned}
\frac{\partial \mathscr{L}}{\partial \zeta_{h s}} & =\beta^{s-1} \prod_{j=1}^{s} \phi_{j}\left[-w \lambda_{h s} T C_{h s}^{\prime}\left(\zeta_{h s}\right)+\Gamma_{h s} c_{h s}+\Psi_{h s}\right]=0 \\
0 & =\Psi_{h s} \zeta_{h s} \\
0 & \leq \Psi_{h s} \\
1 & \geq \zeta_{h s}
\end{aligned}
$$

Therefore:

$$
\begin{cases}\lambda_{h s} w T C_{h s}^{\prime}\left(\zeta_{h s}\right)=\Gamma_{h s} c_{h s} & \text { if } 0<\zeta_{h s}<1 \\ \lambda_{h s} w T C_{h s}^{\prime}\left(\zeta_{h s}\right) \geq \Gamma_{h s} c_{h s} & \text { if } \zeta_{h s}=0\end{cases}
$$

The first-order condition for consumption is:

$$
\frac{\partial \mathscr{L}}{\partial c_{h s}}=\beta^{s-1} \prod_{j=1}^{s} \phi_{j}\left[c_{h s}^{-\sigma}-\lambda_{h s}-\left(1-\zeta_{h s}\right) \Gamma_{h s}\right]=0,
$$

implying

$$
c_{h s}^{-\sigma}=\lambda_{h s}+\left(1-\zeta_{h s}\right) \Gamma_{h s} .
$$

The first-order condition with respect to $k_{h s+1}$ implies

$$
\lambda_{h s}=\beta \phi_{s+1} \lambda_{h s+1}\left(1+\left(1-\tau_{r}\right) r\right),
$$

and the first-order conditions with respect to $m_{h s+1}$ derives from

$$
\frac{\partial \mathscr{L}}{\partial m_{h s+1}}=\beta^{s-1} \prod_{j=1}^{s} \phi_{j}\left[-\pi \lambda_{h s}+\beta \phi_{s+1}\left(\lambda_{h s+1}+\Gamma_{h s+1}\right)\right]=0
$$

which implies

$$
\lambda_{h s}=(\beta / \pi) \phi_{s+1}\left(\lambda_{h s+1}+\Gamma_{h s+1}\right) .
$$

Combining (39) and (41) gives

$$
Q:=\pi\left(1+\left(1-\tau_{r}\right) r\right)=\frac{\lambda_{h s+1}+\Gamma_{h s+1}}{\lambda_{h s+1}} .
$$

Since the nominal interest factor $Q$ is constant in the stationary solution this also implies

$$
\Gamma_{h s}=(Q-1) \lambda_{h s}, \quad s=1,2, \ldots, T .
$$


Furthermore, if $Q>1$ the cash-in-advance constraint binds for all $s=1,2, \ldots, T$. This allows us to put

$$
m_{h s}=\left(1-\zeta_{h s}\right) c_{h s}
$$

(38) and (43) can be combined to yield

$$
c_{h s}^{-\sigma}=\lambda_{h s}\left(1+\left(1-\zeta_{h s}\right)(Q-1)\right)
$$

Substituting for $\Gamma_{h s}$ in (36) from (43) yields

$$
w T C_{h s}^{\prime}\left(\zeta_{h s}\right)=(Q-1) c_{h s}
$$

In addition to (44), (45), (46) the budget constraint must be satisfied

$$
\begin{aligned}
c_{h s}= & \left(1-\tau_{w}-\theta\right) e_{s} z_{h} w+b_{h s}+\left(1+\left(1-\tau_{r}\right) r\right) k_{h s}+m_{h s}+t r \\
& -w T C_{h s}\left(\zeta_{h s}\right)-k_{h s+1}-\pi m_{h s+1} .
\end{aligned}
$$

Computational strategy. Suppose we have initial values for the households' stock of capital $k_{h s}, h=1,2, \ldots, m, s=2,3, \ldots, T$ and their consumption $c_{h s}, h=1,2, \ldots, m$, $s=1,2, \ldots, T$. Our purpose is to set up a non-linear system of equations that can be solved numerically.

Step 1: Is equivalent to Step 1 in the MIUF model. In addition to the variables computed there, we solve for $Q$ from

$$
Q=\pi\left(1+\left(1-\tau_{r}\right) r\right)
$$

Step 2: Given $w, Q$ and $c_{h s}$ we can solve for $\zeta_{h s}$ from (45):

$$
\frac{(Q-1) c_{h s}}{\kappa_{0} w}-\frac{\kappa_{1}}{\kappa_{0} c_{h s}}=\left(\frac{\zeta_{h s}}{1-\zeta_{h s}}\right)^{\chi} .
$$

At this point, we will stop, if the lhs of this equation is negative. If it happens to be zero we put $\zeta_{h s}=0$. Otherwise we can solve for $\zeta_{h s} \in(0,1)$. Given this solution we can compute

$$
m_{h s}=\left(1-\zeta_{h s}\right) c_{h s} .
$$

Step 3: Since we now know $m_{h s}$ we are able to compute seignorage and aggregate bequests. From these magnitudes we derive the transfer payments via (31). 
Step 4: We compute individual consumption from the agents' budget constraints and subtract the result from the given initial $c_{h s}$. This supplies $m T$ equations in the unknown consumption vector. In doing so we use Gauss-Chebyshev integration to compute $T C_{h s}$.

Step 5: The further $m(T-1)$ equations in the unknown individual capital stocks are derived from (44):

$$
\left(\frac{c_{h s+1}}{c_{h s}}\right)^{-\sigma}-\frac{\lambda_{h s+1}}{\lambda_{h s}} \frac{1+\left(1-\zeta_{h s+1}\right)(Q-1)}{1+\left(1-\zeta_{h s}\right)(Q-1)}=0
$$

Since

$$
\frac{\lambda_{h s+1}}{\lambda_{h s}}=\frac{1}{\beta \phi_{s+1}\left(1+\left(1-\tau_{r}\right) r\right)}
$$

we get:

$$
\beta \phi_{s+1}\left(1+\left(1-\tau_{r}\right) r\right)\left(\frac{c_{h s+1}}{c_{h s}}\right)^{-\sigma}-\frac{1+\left(1-\zeta_{h s+1}\right)(Q-1)}{1+\left(1-\zeta_{h s}\right)(Q-1)}=0 .
$$

As starting values for consumption and capital we use the solution of the same model that we use to initialize the non-linear equations solver in the case of the MIUF-model. Having found a solution for $\kappa_{1}=0$ we choose

$$
\kappa_{1}<\frac{(Q-1) c^{2}}{w}
$$

where $c$ is the minimum of consumption over all ages and productivity types. This choice of $\kappa_{1}$ allows us to use the solution for consumption in the case of $\kappa_{1}=0$ to compute $\zeta_{h s}$. Since the upper limit of $\kappa_{1}$ turned out to be very small and further increases of $\kappa_{1}$ did not increase $c$ it was not possible to compute the model's solution for $\kappa_{1}>0.0019$.

\subsection{Limited participation}

Aggregate relations. Money supply $M_{t}$ grows at the constant rate $\mu$. In the stationary equilibrium the price level $P_{t}$ evolves according to $P_{t+1} / P_{t}=\pi=1+\mu$. Let $Q_{t}$ denote the nominal interest factor, $w_{t} N_{t}$ the aggregate real wage bill, $D_{t}$ the nominal aggregate amount of bank deposits and $X_{t}$ the nominal aggregate level of money holdings. Total nominal lending of banks to firms is $D_{t}+(\pi-1) M_{t}$ so that

$$
w_{t} N_{t}=\frac{D_{t}+(\pi-1) M_{t}}{P_{t}}
$$


The profits of banks amount to

$$
\Omega_{t}=Q_{t}(\pi-1) \frac{M_{t}}{P_{t}} .
$$

Profit maximization of producers implies

$$
\begin{aligned}
Q_{t} w_{t} & =(1-\alpha) N_{t}^{-\alpha} K_{t}^{\alpha}, \\
r_{t} & =\alpha N_{t}^{1-\alpha} K_{t}^{\alpha-1}-\delta .
\end{aligned}
$$

In the stationary equilibrium of the model we can drop all time indices from the above equations. For further reference we define

$$
\tilde{r}:=\left(1+\left(1-\tau_{r}\right) r\right)>1 .
$$

First order conditions. In the following we omit the index of the productivity type $h$ as well as the index of calendar time $t$ and consider the problem faced by an agent of age $s=1$ who is born into a stationary environment. Lower case letters denote individual as opposed to aggregate variables. $d_{s}$ and $x_{s}$ are the agent's real bank deposits and real money holdings, respectively. Both are measured in terms of the current period price level so that $\pi d_{s+1}$ and $\pi x_{s+1}$ are bank deposits and money holdings acquired at age $s$ and put aside for age $s+1$.

The Lagrangian of the agent is:

$$
\begin{aligned}
\mathscr{L} & =\sum_{s=1}^{T} \beta^{s-1} \prod_{j=1}^{s} \phi_{j} \frac{c_{s}^{1-\sigma}}{1-\sigma} \\
& +\sum_{s=1}^{R-1} \beta^{s-1} \prod_{j=1}^{s} \phi_{j}\left[\left(1-\tau_{w}-\theta\right) e_{s} z w+\tilde{r} k_{s}+t r+\omega+x_{s}+d_{s}\left(1-\tau_{r}\right)(Q-1)\right. \\
& \left.\quad-c_{s}-k_{s+1}-\pi\left(x_{s+1}+d_{s+1}\right)\right] \lambda_{s} \\
& +\sum_{s=R}^{T} \beta^{s-1} \prod_{j=1}^{s} \phi_{j}\left[\bar{b}+\tilde{r} k_{s}+t r+\omega+x_{s}+d_{s}\left(1-\tau_{r}\right)(Q-1)\right. \\
& \left.\quad-c_{s}-k_{s+1}-\pi\left(x_{s+1}+d_{s+1}\right)\right] \lambda_{s} \\
+ & \sum_{s=1}^{R-1} \beta^{s-1} \prod_{j=1}^{s} \phi_{j}\left[\Gamma_{s}\left(x_{s}+\left(1-\tau_{w}-\theta\right) e_{s} z w-c_{s}\right)\right] \\
+ & \sum_{s=R}^{T} \beta^{s-1} \prod_{j=1}^{s} \phi_{j}\left[\Gamma_{s}\left(x_{s}+\bar{b}-c_{s}\right)\right]+\sum_{s=1}^{T-1} \beta^{s-1} \prod_{j=1}^{s} \phi_{j} \xi_{s+1} x_{s+1} .
\end{aligned}
$$


The first-order condition for consumption is:

$$
\frac{\partial \mathscr{L}}{\partial c_{s}}=\beta^{s-1} \prod_{j=1}^{s} \phi_{j}\left[c_{s}^{-\sigma}-\lambda_{s}-\Gamma_{s}\right]=0,
$$

implying

$$
c_{s}^{-\sigma}=\lambda_{s}+\Gamma_{s}
$$

The first-order condition with respect to $k_{s+1}$ implies

$$
\lambda_{s}=\beta \phi_{s+1} \lambda_{s+1} \tilde{r}
$$

Setting to zero the derivatives of $(55)$ with respect to $x_{s+1}$ and $d_{s+1}$ delivers:

$$
\begin{aligned}
& \lambda_{s}=(\beta / \pi) \phi_{s+1}\left(\lambda_{s+1}+\Gamma_{s+1}\right)+(1 / \pi) \xi_{s+1}, \\
& \lambda_{s}=(\beta / \pi) \phi_{s+1} \lambda_{s+1}\left(1+(Q-1)\left(1-\tau_{r}\right)\right) .
\end{aligned}
$$

In addition, there are the slackness conditions of the cash-in-advance constraint,

$$
\begin{array}{ll}
0 \leq \Gamma_{s}, & \\
0=\Gamma_{s}\left(x_{s}+\left(1-\tau_{w}-\theta\right) e_{s} z w-c_{s}\right), & \text { for } s=1, \ldots, R-1, \\
0=\Gamma_{s}\left(x_{s}+b-c_{s}\right), & \text { for } s=R, \ldots, T .
\end{array}
$$

and of the non-negativity constraint on cash balances:

$$
\begin{array}{ll}
0 \leq \xi_{s+1}, & \text { for } s=1,2, \ldots, T-1, \\
0=\xi_{s+1} x_{s+1}, & \text { for } s=1,2, \ldots, T-1 .
\end{array}
$$

Implications. Combining (56b) and (56d) gives

$$
\tilde{r}=\left(1+\left(1-\tau_{r}\right) r\right)=\left(1+(Q-1)\left(1-\tau_{r}\right)\right) / \pi .
$$

This condition implies that we are not able to solve for $d_{s}$. Therefore, we define the households interest bearing assets as

$$
a_{s}:=k_{s}+d_{s} / \pi
$$


This allows us to write the budget constraint as

$$
a_{s+1}= \begin{cases}\left(1-\tau_{w}-\theta\right) e_{s} z w+\tilde{r} a_{s}+\omega+t r+x_{s}-\pi x_{s+1}-c_{s}, & \text { for } s=1, \ldots, R-1 \\ \bar{b}+\tilde{r} a_{s}+\omega+t r+x_{s}-\pi x_{s+1}-c_{s}, & \text { for } s=R, \ldots T .\end{cases}
$$

Note that whenever the cash-in-advance constraint does not bind real cash balances will be zero. To see this, assume $x_{s+1}>0$ and $c_{s+1}<\left(1-\tau_{w}-\theta\right) e_{s+1} z w n$ so that $\xi_{s+1}=\Gamma_{s+1}=0$. This yields $\lambda_{s}=(\beta / \pi) \phi_{s+1} \lambda_{s+1}$ from (56c). Yet, since $\pi \tilde{r}>1$ this contradicts condition (56b).

The government's budget constraint. Let

$$
A:=\sum_{s=1}^{T} \sum_{h=1}^{m} \psi_{s} \nu_{h} a_{s h}
$$

denote aggregate interest bearing assets. Aggregate income from capital taxation is given by

$$
\operatorname{Tax}=\tau_{r} r K+\tau_{r}(Q-1)(D / P),
$$

where

$$
K=A-(D / P) / \pi
$$

Note, that we are not able to write the rhs of this equation as $r A$ since $\pi r \neq(Q-1)$. Aggregate bequests are given by

$$
B e q=\sum_{s=1}^{T-1}\left(1-\phi_{s+1}\right) \sum_{h=1}^{m} \psi_{s} \nu_{h}\left(a_{h s+1}+\pi x_{h s+1}\right) .
$$

Thus, aggregate transfers (which equal individual transfers $t r$ since the total mass of all living agents is normalized to unity) are derived from

$$
t r=T a x+B e q-G .
$$


Computational strategy. Suppose we have initial values for the aggregate stock of capital $K_{0}$, the aggregate level of real money balances $(M / P)_{0}$, the aggregate level of bequests $B e q_{0}$, the consumption of generation $s=1, c_{1 h}, h=1,2, \ldots, m$, as well as the Lagrange multiplier of the first-year budget constraint $\lambda_{1 h}, h=1,2, \ldots, m$. We derive new values for these variables in the following steps.

Step 1: Since $N$ is only a function of given parameters (see (22)), we are able to compute

$$
\begin{aligned}
& Y=N^{1-\alpha} K^{\alpha}, \\
& G=g Y,
\end{aligned}
$$

(where $g=0.195$ ) as well as

- $r$ via (53a),

- $Q$ via (35),

- $w$ via (53b),

- $\Omega \equiv \omega$ via $(52)$

- $D / P$ via $(51)$,

- $\bar{b}_{h}$ via the pension scheme $(21)$.

Given these variables we are in the position to compute $t r$ from equations (59b) and (59e) as well as $\theta=$ Pens $/(w N)$, where Pens $=\sum_{s=R}^{T} \sum_{h=1}^{l} \psi_{s} \nu_{h} \bar{b}_{h}$. Thus all variables that are exogenous to the individual budget constraint are known.

Step 2: We check the cash-in-advance constraint for generation $s=1$ : If $c_{1 h}<\left(1-\tau_{w}-\right.$ $\theta) e_{s} z_{h} w n$, condition (56a) applies with $\Gamma_{1 h}=0$, else the cash-in-advance constraint applies: $c_{1 h}-\left(1-\tau_{w}-\theta\right) e_{s} z_{h} w n=0$. This delivers $m$ conditions for our $2 m+3$ unknowns.

Step 3: We compute consumption, cash balances, and interest bearing assets for all generations. Given $\lambda_{1 h}$ we compute the sequence of Lagrange multipliers from (56b). For each $s$ we first assume $x_{s h}>0$ (and, thus, that the cash-in-advance constraint binds). In this case we get

$$
c_{s h}=\left(\frac{\pi \lambda_{s-1}}{\beta \phi_{s}}\right)^{-1 / \sigma} \text {. }
$$


form (56a) and (56c). If

$$
c_{s h}> \begin{cases}\left(1-\tau_{w}-\theta\right) e_{s} z_{h} w n & \text { for } s=2, \ldots, R-1, \\ \bar{b}_{h} & \text { for } s=R, \ldots, T\end{cases}
$$

we compute the cash balances of the $s$ year old household from

$$
x_{s h}=\left\{\begin{array}{ll}
c_{s h}-\left(1-\tau_{w}-\theta\right) e_{s} z_{h} w n & \text { for } s=2, \ldots, R-1, \\
c_{s h}-\bar{b}_{h} & \text { for } s=R, \ldots, T
\end{array} .\right.
$$

If condition (61) does not apply, $x_{s h}=0$ and $\Gamma_{s h}=0$ so that (56a) and (56b) imply

$$
c_{s h}=\left(\frac{\lambda_{s-1}}{\beta \phi_{s} \tilde{r}}\right)^{-1 / \sigma}
$$

Given consumption and cash balances, we compute interest bearing assets from

$a_{s h}= \begin{cases}\left(1-\tau_{w}-\theta\right) e_{s-1} z_{h} w n+\tilde{r} a_{s-1 h}+\omega+t r+x_{s-1 h}-\pi x_{s h}-c_{s-1 h} & \text { for } s=2, \ldots, R-1, \\ \bar{b}_{h}+\tilde{r} a_{s-1 h}+\omega+t r+x_{s-1 h}-\pi x_{s h}-c_{s-1 h} & \text { for } s=R, \ldots, T\end{cases}$

The budget constraints of the $T$ year old households imply $m$ further conditions:

$$
0=\bar{b}_{h}+\tilde{r} a_{T h}+\omega+t r+x_{T h}-c_{T h}
$$

Step 4: Finally, we compute the aggregate variables: Via (59a) we compute aggregate wealth and - since $D / P=w N-(\pi-1)(M / P)_{0}$ - we get $K_{1}=A-(D / P) / \pi$. From $(59 \mathrm{~d})$ we get $B e q_{1}$. Furthermore

$$
(M / P)_{1}=D / P+\sum_{s=2}^{T} \sum_{h=1}^{m} \psi_{s} \nu_{h} x_{h s} .
$$

Thus, we have these additional three equations:

$$
\begin{aligned}
& 0=K_{1}-K_{0}, \\
& 0=(M / P)_{1}-(M / P)_{0}, \\
& 0=B e q_{1}-B e q_{0} .
\end{aligned}
$$

We solve this system with a non-linear equations solver using initial values on $K, B e q, c_{1 h}$, and $\lambda_{1 h}=c_{1 h}^{-1 / \sigma}$ from our baseline model without money. 
To compute the agent's gross income,

$$
y_{h s}= \begin{cases}\left(1-\tau_{w}-\theta\right) e_{s} z_{h} w+\tilde{r} k_{h s}+(R-1)\left(1-\tau_{r}\right) d_{h s}+\omega+t r & \text { for } s=1, \ldots, R-1, \\ \bar{b}_{h}+\tilde{r} k_{h s}+(Q-1)\left(1-\tau_{r}\right) d_{h s}+\omega+t r, & \text { for } s=R, \ldots, T\end{cases}
$$

we assume $d_{h s}=(D / X) x_{h s}$ for all $s$ and $h$. 